\title{
Neurobeachin: A Protein Kinase A-Anchoring, beige/Chediak- Higashi Protein Homolog Implicated in Neuronal Membrane Traffic
}

\author{
Xiaolu Wang, ${ }^{1}$ Friedrich W. Herberg, ${ }^{1}$ Michael M. Laue, ${ }^{1}$ Christiane Wüllner, ${ }^{1}$ Bin Hu, ${ }^{1}$ \\ Elisabeth Petrasch-Parwez, ${ }^{2}$ and Manfred W. Kilimann ${ }^{1}$ \\ 1/nstitut für Physiologische Chemie and 2Institut für Anatomie, Ruhr-Universität Bochum, D-44780 Bochum, Germany
}

\begin{abstract}
We describe the identification and initial characterization of neurobeachin, a neuron-specific multidomain protein of $327 \mathrm{kDa}$ with a high-affinity binding site $\left(K_{d}, 10 \mathrm{nM}\right)$ for the type II regulatory subunit of protein kinase A (PKA RII). Neurobeachin is peripherally associated with pleomorphic tubulovesicular endomembranes near the trans sides of Golgi stacks and throughout the cell body and cell processes. It is also found in a subpopulation of synapses, where it is concentrated at the postsynaptic plasma membrane. In live cells, perinuclear neurobeachin is dispersed by brefeldin A (BFA) within $1 \mathrm{~min}$, and in permeabilized cells a recruitment of neurobeachin from cytosol to Golgi-near membranes is stimulated by GTP $\gamma \mathrm{S}$ and prevented by brefeldin A. Spots of neurobeachin recruitment are close to but distinct from recruitment sites of COP-I, AP-1, and AP-3 coat proteins involved in vesicle budding. These observations indicate that neurobeachin binding to membranes close to the trans-Golgi requires an ADP-ribosylation factor-like GTPase, possibly in association with a novel type of protein coat. A neurobeachin
\end{abstract}

The progression of membranes and proteins through the stages and compartments of the secretory and endocytic pathways is a highly organized and regulated process. The maintenance of the overall architecture of endomembranes and of the plasma membrane requires a balance of lipid flows into and out of the various compartments, and proteins destined for diverse organelles or plasma membrane domains must be appropriately sorted and targeted, whereas resident proteins of specific pathway stages must be retained or retrieved. These events require the interplay of lipids, membrane proteins, soluble cytosolic and lumenal proteins, and cytoskeletal and motor proteins. Their internal coordination and external regulation is known to involve protein phosphorylation and small and heterotrimeric G-proteins.

In neurons, the mechanisms for the trafficking of membranes and membrane proteins must be particularly active and complex. Because of their many and long cell extensions, neurons have to build up and maintain a very large plasma membrane area that is organized not only into the somatodendritic and axonal macrodomains but additionally into an elaborate mosaic of microdomains with specific protein compositions, particularly at presynaptic and postsynaptic sites (Foletti et al., 1999).

Received April 25, 2000; revised Aug. 11, 2000; accepted Aug. 28, 2000.

This work was supported by grants from the Deutsche Forschungsgemeinschaft and the University of Bochum Medical School (FoRUM intramural research funding program) to M.W.K. and F.W.H., and from the Fonds der Chemischen Industrie to M.W.K. We thank A. Toth for the performance of some SPR experiments, K. Meller and C. Theiss for fluorescence video microscopy, G. Papoutsoglou and N. Opitz for confocal microscopy, K. von Figura and M. Hannah for critical reading of this manuscript, and M. Robinson and W. Huttner for discussions. We are indebted to J. Saraste, B. L. Tang, W. Hong, S. Fuller, M. Zerial, W. Huttner, A. Helenius, M. Renz, M. Robinson, R. Darnell, A. Hille-Rehberg, P. Saftig, K. von Figura, R. Jahn, W. H. Kunau, V. Lessmann, and E. Klussmann for marker antibodies, and to S. S. Taylor and $\mathrm{K}$. Tasken for $\mathrm{R}$ subunit reagents.

Correspondence should be addressed to Dr. Manfred W. Kilimann, Institut für Physiologische Chemie, Ruhr-Universität Bochum, Universitätsstrasse 150, D-44801 Bochum, Germany. E-mail: manfred.kilimann@ruhr-uni-bochum.de.

Copyright (C) 2000 Society for Neuroscience $0270-6474 / 00 / 208551-15 \$ 15.00 / 0$ isoform that does not bind RIl, beige-like protein (BGL), is expressed in many tissues. Neurobeachin, BGL, and $\sim 10$ other mammalian gene products share a characteristic C-terminal $\mathrm{BEACH}-\mathrm{WD} 40$ sequence module, which is also present in gene products of invertebrates, plants, protozoans, and yeasts, thus defining a new protein family. The prototype member of this family of BEACH domain proteins, lysosomal trafficking regulator (LYST), is deficient in genetic defects of protein sorting in lysosome biogenesis (the beige mouse and Chediak-Higashi syndrome). Neurobeachin's subcellular localization, its coat proteinlike membrane recruitment, and its sequence similarity to LYST suggest an involvement in neuronal post-Golgi membrane traffic, one of its functions being to recruit protein kinase $A$ to the membranes with which it associates.

Key words: AKAP; ARF; BEACH domain; BGL; coat protein; Golgi complex; LYST; membrane traffic; neurobeachin; protein kinase A; scaffolding protein; synapse; TGN
Protein kinase A (PKA) is the collective term for an enzyme family comprising three catalytic subunit isoforms and four regulatory subunit isoforms. PKA is regulated through the second messenger, cAMP, in response to many extracellular signals and in turn acts on a vast variety of intracellular events, including different pathways and stages of membrane traffic (Ohashi and Huttner, 1994; Muniz et al., 1997). The targeting of PKA actions to specific subcellular sites and substrate proteins is thought to be mediated in part by A-kinase anchor proteins (AKAPs) (Colledge and Scott, 1999). AKAPs are a large and diverse group of proteins that reside at distinct subcellular locations and possess high-affinity binding sites for the type II regulatory subunit isoforms (RII $\alpha$ and RII $\beta$ ) of PKA. By this way, they concentrate the inactive PKA holoenzyme at these sites, and a rise in cAMP causes the local release of free, active catalytic subunits that then phosphorylate substrate proteins in their vicinity. AKAPs have been found to be associated, e.g., with the plasma membrane, the endoplasmic reticulum, the nuclear membrane, microfilaments, microtubules, mitochondria, peroxisomes, centrosomes, or postsynaptic sites and are implicated in the PKA-regulation of physiological events such as sperm motility, insulin secretion, the modulation of neurotransmitter receptors and ion channels, and the exocytosis of water channel-carrying vesicles in kidney cells.

In the present study, we report the identification and initial characterization of neurobeachin, a novel neuron-specific protein and AKAP. We initially identified neurobeachin as a component of synapses, but find most of it associated with tubulovesicular endomembranes throughout neuronal cell bodies and dendrites and concentrated near the trans-Golgi. Neurobeachin is a large multidomain protein that is recruited from cytosol to Golgi-near membranes in a coat protein-like, GTP-dependent, and brefeldin A (BFA)-sensitive fashion, suggesting an involvement in membrane traffic. Neurobeachin also contains a BEACH-WD40 sequence module. This makes it the third member to be characterized of an emerging family of $\sim 10$ distinct mammalian proteins with 
BEACH-WD40 domains. The prototype of this family is lysosomal trafficking regulator (LYST), a cytosolic protein important for lysosomal biogenesis and implicated in protein sorting between endosomes, lysosomes, and the plasma membrane.

\section{MATERIALS AND METHODS}

cDNA cloning and Northern blot analysis. The chicken cDNA clone, 10.2, was isolated by immunoscreening a brain cDNA library in $\lambda$ gt11 as described by Lichte et al. (1992). It contained an uninterrupted coding sequence of 2379 nucleotides (nts) and was used as a hybridization probe to screen a mouse cDNA library in $\lambda$ ZAP-II (Stratagene, La Jolla, CA). Drosophila expressed sequence tags (ESTs) from the Berkeley Drosophila Genome Project were identified by sequence database search with the mouse neurobeachin sequence and obtained through Genome Systems, Inc. Clone LD07020 was found to overlap with the published DAKAP550 sequence and extend it farther downstream. Clone HL06008 did not overlap but displayed $80 \%$ predicted amino acid sequence identity in the downstream half of the neurobeachin BEACH sequence. We bridged the interval between the two clones by RT-PCR from Drosophila head RNA and thus determined the complete $\mathrm{C}$-terminal coding sequence of DAKAP550.

Total and poly $\left(\mathrm{A}^{+}\right)$RNA preparation from chicken and mouse tissues and Northern blot analysis with ${ }^{32} \mathrm{P}$-labeled hybridization probes were performed according to conventional procedures. To analyze developmental expression of neurobeachin mRNA, Northern blots were loaded with 20 $\mu \mathrm{g}$ of total RNA from mouse brains of postnatal days $1,5,10,15,20,25$, 30, 56, and 150 (Kutzleb et al., 1998). Forskolin/3-isobutyl-1-methylxanthine (IBMX) treatment and Northern blot analysis of NS20Y mouse neuroblastoma cells were performed as in Hoesche et al. (1995). Chicken blots were hybridized with clone 10.2, and mouse blots were hybridized with the RT-PCR product of mouse neurobeachin region B that was also used for expression constructs (see below).

Antibody production, immunoblotting, and subcellular fractionation. Regions B of neurobeachin (amino acids 951-1311) and beige-like protein (BGL) (amino acids 169-526) were amplified by RT-PCR from mouse brain and human heart RNA, respectively, and subcloned into the SmaI site of the His-tag vectors pQE31 and pQE32 (Qiagen, Hilden, Germany), respectively. Subclone inserts were completely sequenced to confirm the absence of mutations. His-tag fusion proteins were expressed in bacteria, purified on nickel agarose, and used for immunization of rabbits and hens. Sera were affinity-purified using the same fusion proteins coupled to tresyl chloride-activated Sepharose (Sigma, St. Louis, MO).

To determine the tissue distribution of neurobeachin, tissues were homogenized in $0.32 \mathrm{M}$ sucrose, $1 \mathrm{~mm}$ EDTA, $10 \mathrm{~mm}$ Tris, $\mathrm{pH} 7.4,0.5 \mathrm{~mm}$ PMSF, $2 \mu \mathrm{g} / \mathrm{ml}$ pepstatin A, $2 \mu \mathrm{g} / \mathrm{ml}$ leupeptin, with a glass-Teflon homogenizer or, for muscle and heart, a turning-knife homogenizer. Cultured cells were rinsed with PBS, scraped from the dish in $20 \mathrm{~mm}$ Tris, $\mathrm{pH} 7.4,2 \mathrm{~mm}$ EDTA, $0.5 \mathrm{~mm}$ PMSF, $2 \mu \mathrm{g} / \mathrm{ml}$ pepstatin A, $2 \mu \mathrm{g} / \mathrm{ml}$ leupeptin, and sheared by 10 passages through a G27 syringe. After spinning for $3 \mathrm{~min}$ at $900 \times \mathrm{g}, 80 \mu \mathrm{g}$ of protein of each supernatant was subjected to SDS-PAGE (5\% polyacrylamide) and transferred to nitrocellulose, and the blot was developed with affinity-purified rabbit antineurobeachin and the ECL kit (Amersham, Arlington Heights, IL). The minor bands visible below the main band on Figure $5 B$ are attributed to partial proteolysis of this large protein and can be avoided under other circumstances.

For subcellular fractionation, $900 \times g$ supernatants of brain homogenates (in $150 \mathrm{~mm} \mathrm{NaCl}, 1 \mathrm{~mm}$ EDTA, $10 \mathrm{~mm}$ Tris, pH 7.4, 0.5 mM PMSF, $2 \mu \mathrm{g} / \mathrm{ml}$ pepstatin A, $2 \mu \mathrm{g} / \mathrm{ml}$ leupeptin) were subjected to a $120,000 \times g$ centrifugation for $30 \mathrm{~min}$ at $4^{\circ} \mathrm{C}$. Pellets were washed by resuspending in homogenization buffer followed by a second 120,000 $\times \mathrm{g}$ spin and then resuspended either in homogenization buffer or in various solubilization buffers (see Fig. 12 legend), either for $20 \mathrm{~min}$ at $4^{\circ} \mathrm{C}$ or for $30 \mathrm{~min}$ at room temperature. The $120,000 \times g$ centrifugation was then repeated. Equal aliquots of pellets and supernatants were analyzed by immunoblotting as described above.

Immunohistochemistry for light and electron microscopy. Peroxidaseimmunocytochemical analysis of rat brain by light and electron microscopy was performed as described previously (Kutzleb et al., 1998). For preembedding immunogold electron microscopy, vibratome sections of rat cerebellum were incubated with neurobeachin antibodies as in the peroxidase-labeling experiments. After the neurobeachin antibodies were washed out, sections were blocked with $0.2 \%$ cold-water fish gelatin (Sig$\mathrm{ma}$ ), $0.25 \% \mathrm{BSA}$, and $1 \%$ normal goat serum in PBS and then immersed for $20 \mathrm{hr}$ in a solution of goat anti-rabbit Fab' fragments coupled to small gold particles (Nanoprobes; 1:800 in blocking solution). Unbound antibodies were washed out with blocking solution followed by PBS, and bound antibodies were fixed with $1 \%$ glutaraldehyde in PBS for $1 \mathrm{hr}$. Silver intensification according to Burry et al. (1992) was performed for $13 \mathrm{~min}$ at room temperature to enlarge gold particles to detectable size. Dehydration of sections, subsequent embedding in araldite, and ultrathin sectioning were performed as for peroxidase immunocytochemistry (Kutzleb et al., 1998).

Immunofluorescence and treatments with $\mathrm{BFA}$ and $\mathrm{AlF}_{4}{ }^{-}$. NS20Y, COS-7, and $\mathrm{L} 929$ cells were grown at $37^{\circ} \mathrm{C}$ and $8 \% \mathrm{CO}_{2}$ in DMEM supplemented with $10 \% \mathrm{FCS}$ and $50 \mu \mathrm{g} / \mathrm{ml}$ streptomycin, $50 \mathrm{IU} / \mathrm{ml}$ peni- cillin, $2 \mathrm{~mm}$ L-glutamine, $1 \mathrm{~mm}$ pyruvate. For PC12 cells, serum concentrations were $5 \%$ fetal calf serum and $10 \%$ horse serum. For drug treatments of PC12 cells, BFA (final concentration, $50 \mu \mathrm{M}$ ) or $\mathrm{AlF}_{4}{ }^{-}(30 \mathrm{mM}$ $\mathrm{NaF}+50 \mu \mathrm{M} \mathrm{AlCl}_{3}$ ) were added to the culture media, and the cells were further incubated at $37^{\circ} \mathrm{C}$ and $8 \% \mathrm{CO}_{2}$ for the indicated times before fixation.

Immunofluorescence analysis was performed essentially as described (Kutzleb et al., 1998). NS20Y and PC12 cells were fixed in 4\% paraformaldehyde in PBS and permeabilized with 0.02 or $0.04 \%$ saponin. For double-labeling experiments, cells were incubated simultaneously with both primary antibodies, which were then visualized with Cy3-labeled secondary antibodies or with biotinylated secondary antibodies followed by streptavidin-FITC. Specimens were inspected with a Zeiss Axiophot II microscope and in some instances, when neurobeachin and marker patterns were similar, additionally by confocal microscopy.

In most instances, affinity-purified rabbit anti-neurobeachin was used for immunofluorescence in combination with mouse marker antibodies; affinity-purified hen anti-neurobeachin was used in combination with rabbit marker antibodies. Two different rabbit antibodies gave similar patterns of endogenous neurobeachin in PC12 cells, and rabbit and hen antibodies produced coincident patterns in double immunofluorescence. Also, the characteristic pattern of neurobeachin recruitment to Golgi-near membranes in COS-7 cells was seen concordantly with two rabbit and one hen antibodies, and neurobeachin scattering by BFA in live PC12 cells was observed with two different rabbit antibodies. Neurobeachin immunofluorescence was abolished by preincubation of the antibodies with neurobeachin region B but not by BGL region B. Preimmune controls were also negative.

Marker antibodies were generous gifts of J. Saraste (p58), B. L. Tang and W. Hong (KDEL receptor and mSec13), S. Fuller (PDI, clone 1D3), A. Helenius (calnexin), M. Renz (giantin), M. Robinson ( $\gamma$-adaptin, $\delta$-adaptin, and clathrin heavy chain affinity-purified sera), R. Darnell ( $\beta 3$ B-adaptin/ $\beta$-NAP affinity-purified serum), M. Zerial (Rab5, Rab7), A. Hille-Rehberg and K. von Figura (M6PR-300), V. Lessmann and W. Huttner (secretogranin II), R. Jahn [cellubrevin (serum R54) and synaptobrevin 2], W. H. Kunau (GFP), and P. Saftig (Limp-2), or were obtained commercially from Babco (Richmond, CA) (mannosidase II), Santa Cruz Biotechnology (Santa Cruz, CA) [Rab1A (C-19) and RII $\alpha$ sera], Sigma $[\beta$-COP $\mathrm{mAb}$ (clone maD) and $\gamma$-tubulin serum], the Developmental Studies Hybridoma Bank at the University of Iowa (Lamp-1, clone 1D4B), Transduction Labs (Rab3, Rab4, $\beta$-NAP, EEA1, TGN38, RII $\alpha$, and RII $\beta$ mAbs), Amersham ( $\alpha$-tubulin mAb), Molecular Probes (Eugene, OR) (cytochrome $c$ oxidase mAb 1D6-E1-A8), Zymed (San Francisco, CA) (transferrin receptor), Chemicon (Temecula, CA) (N-CAM), and Boehringer Mannheim (Mannheim, Germany) (synaptophysin). Mitotracker was purchased from Molecular Probes.

Protein recruitment from brain cytosol to permeabilized cells. Experiments were performed essentially according to Robinson and Kreis (1992) and Seaman et al. (1993). Cytosol was prepared from rat brain. The tissue was homogenized in 2.5 vol of cytosol buffer ( $25 \mathrm{~mm}$ HEPES-KOH, pH 7.0, $125 \mathrm{~mm}$ KOAc, $2.5 \mathrm{~mm}$ MgOAc, $1 \mathrm{mg} / \mathrm{ml}$ glucose, $100 \mu \mathrm{M}$ EGTA, $1 \mathrm{~mm}$ dithiothreitol) in a glass-Teflon homogenizer. The homogenate was spun at $110,000 \times g$ for $20 \mathrm{~min}$. The supernatant was collected as the cytosol (protein concentration, $\sim 10 \mathrm{mg} / \mathrm{ml}$ ).

For Western blot analysis, COS-7 cells were grown until just confluent in $10 \mathrm{~cm}$ tissue culture dishes. They were washed with cytosol buffer and then frozen by floating the dish on liquid nitrogen for $10 \mathrm{sec}$. After thawing, the cells were scraped up with a rubber policeman and harvested by spinning at $2000 \mathrm{rpm}$ for $3 \mathrm{~min}$. Cells from four dishes were resuspended in cytosol buffer, divided into six aliquots, and centrifuged again. Each aliquot was then resuspended in $200 \mu \mathrm{l}$ of cytosol supplemented, if applicable, with additional reagents as indicated in Figure 10, and incubated for $10 \mathrm{~min}$ at $37^{\circ} \mathrm{C}$. In the case of sequential incubations with GTP $\gamma \mathrm{S}$ and BFA, cells were pelleted and resuspended in the new incubation medium for another $10 \mathrm{~min}$. Cells were finally spun down again and washed with cytosol buffer, and each sample was boiled with $60 \mu \mathrm{l}$ of SDS-PAGE sample buffer from which $15 \mu \mathrm{l}$ aliquots were analyzed by electrophoresis and immunoblotting.

For immunofluorescence microscopic analysis, COS-7 cells were grown to $70 \%$ confluency on collagen-coated coverslips in $6 \mathrm{~cm}$ tissue culture dishes. Coverslips were washed with cytosol buffer and then frozen by floating the dishes on liquid nitrogen for $5 \mathrm{sec}$. After thawing, coverslips were washed briefly with cytosol buffer and then incubated for $10 \mathrm{~min}$ at $37^{\circ} \mathrm{C}$ with cytosol, plus supplements indicated in the legend to Figure 10, or $0.5 \mathrm{~mm} \mathrm{ATP} \gamma \mathrm{S}$, or $\left.\mathrm{AlF}_{4}-(30 \mathrm{~mm} \mathrm{NaF}+50 \mu \mathrm{MAlCl})_{3}\right)$. Specimens were washed again with cytosol buffer, fixed with $4 \%$ paraformaldehyde in cytosol buffer, and processed for immunofluorescence. The characteristic immunofluorescence patterns of recruited proteins were not seen if permeabilized cells were incubated with cytosol buffer only and were seen only in sporadic cells, presumably perforated by handling, if unfrozen cells were incubated with cytosol plus GTP $\gamma \mathrm{S}$ (negative controls).

Coprecipitation of RII and neurobeachin by cAMP-agarose. Rat brain cytosol was prepared as described above (recruitment) and supplemented with $0.1 \%$ Triton X-100 and $0.05 \%$ Tween 20. cAMP-agarose (Sigma A7396, 11-atom spacer with N-6 attachment) was preblocked with 3\% BSA in cytosol buffer at $4^{\circ} \mathrm{C}$ for $1 \mathrm{hr}$ and then washed in cytosol buffer with $0.1 \%$ Triton X-100 and $0.05 \%$ Tween 20. cAMP-agarose (50 $\mu \mathrm{l})$ was incubated 


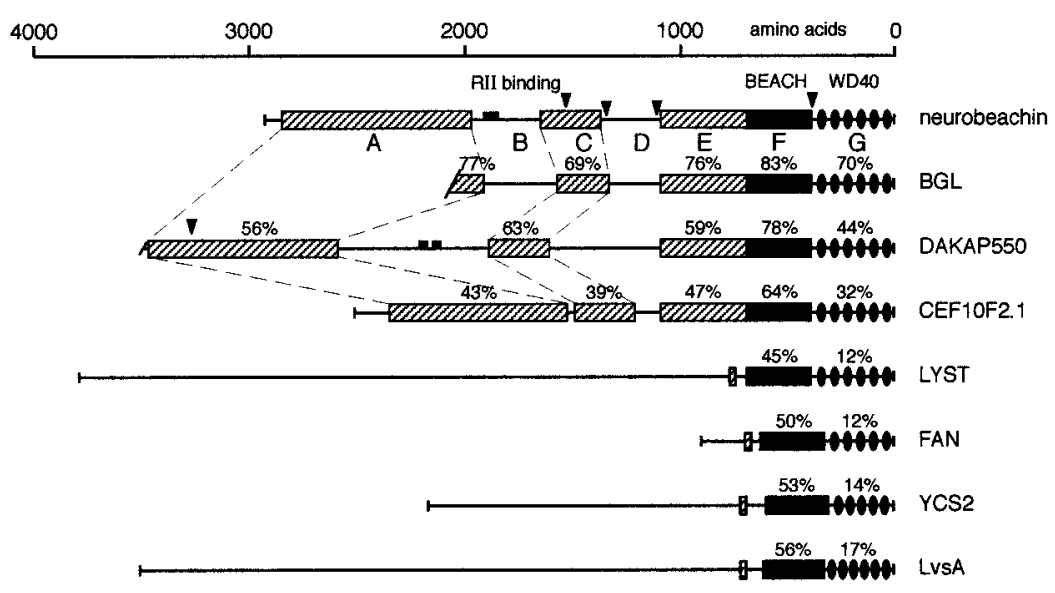

Figure 1. Regional organization of the neurobeachin sequence by alignment with other BEACH-WD40 protein family members. Boxes indicate conserved sequences, and horizontal lines indicate sequences that are poorly or not conserved. The BEACH domain is symbolized by a filled box, and WD40 repeat units by ovoids. Numbers above sequence regions indicate percentage amino acid sequence identity with the corresponding region of neurobeachin. Positions of RII binding sites in neurobeachin and DAKAP550 regions B are marked by small boxes. Sites of apparent differential splicing in neurobeachin and DAKAP550 are marked by triangles. Oblique lines indicate that the N-terminal sequences of BGL and DAKAP550 are incomplete. Note that the amino acid scale begins at the common C terminus. The BGL sequence (accession number M83822) was corrected for a frameshift error in region $\mathrm{G}$ to achieve a predicted $\mathrm{C}$-terminal sequence homologous to neurobeachin. The CEF10F2.1 sequence was obtained by combining two partial predicted reading frames from overlapping cosmids CEF10F2 and CEF35G12 of the Nematode Sequencing Project (accession numbers Z35598 and Z46242) (Wilson et al., 1994). LYST, FAN, YCS2, and LvsA sequences are from Nagle et al. (1996), Adam-Klages et al. (1996), Wicksteed et al. (1991), and Kwak et al. (1999), respectively. with $1 \mathrm{ml}$ cytosol, either with or without addition of $10 \mathrm{mM}$ cAMP (Biolog, Bremen, Germany), for $5 \mathrm{hr}$ at $4^{\circ} \mathrm{C}$ with gentle mixing. Beads were spun down, washed with $6 \times 1.5 \mathrm{ml}$ cytosol buffer, $0.1 \%$ Triton $\mathrm{X}-100,0.05 \%$ Tween 20, and resuspended in SDS-PAGE sample buffer, and aliquots were analyzed by SDS-PAGE and immunoblotting.

RII-neurobeachin binding measured by surface plasmon resonance. Regions $\mathrm{B}$ of mouse neurobeachin and human BGL (as for Northern blot hybridization and immunization constructs; see above) and the corresponding region of Drosophila DAKAP550 (amino acids 1228-1571) were amplified by RT-PCR. Partial sequences within neurobeachin region B, as indicated in Figure $3 E$, were amplified from the full-length region $\mathrm{B}$ subclone as template. Inserts were cloned into pQE plasmids, and subclones used for expression were confirmed to be free of mutations by sequencing. All neurobeachin, BGL, and DAKAP550 fusion proteins were purified under denaturing conditions $(8 \mathrm{M}$ urea) and subsequently renatured by dialysis against decreasing urea concentrations in PBS according to Qiagen protocols. In addition, all neurobeachin constructs were also purified under native conditions $(300 \mathrm{~mm} \mathrm{NaCl})$ according to Qiagen instructions and transferred to PBS by spin-column gel filtration. Binding properties of a given construct prepared both ways were very similar, and the $K_{\mathrm{d}}$ values in Figure $3 E$ are means from both, with the exception of construct $\mathrm{C} 2$, which displayed high-affinity binding only if prepared native $\left(K_{\mathrm{d}}, 20 \mathrm{nM}\right)$ but not if prepared in urea $\left(K_{\mathrm{d}}, 200-900 \mathrm{nM}\right)$.

Surface plasmon resonance (SPR) analysis was performed on a Biacore 2000 instrument. Here, the interaction between an immobilized molecule (the ligand) and a molecule in the mobile phase (the analyte) is determined. Changes in surface concentration of the analyte are proportional to changes in the refractive index on the surface resulting in changes in the SPR signal, plotted as response units (RUs). One thousand RUs correspond to a surface concentration of $1 \mathrm{ng} / \mathrm{mm}^{2}$ (Stenberg et al., 1991). cAMP-free R subunits, expressed in Escherichia coli and prepared according to Buechler et al. (1993), were immobilized to a level of 800-1200 RUs on a carboxymethyldextran surface loaded with 8-amino-hexylaminocAMP (Biolog). RI $\beta$ and RII $\beta$ were gifts of K. Tasken (University of Oslo, Oslo, Norway) and S. S. Taylor (University of California, San Diego, CA), respectively. Interactions were determined in PBS containing $0.005 \%$ surfactant P20 at a flow rate of $10 \mu \mathrm{l} / \mathrm{min}$. Unspecific binding was subtracted by performing blank runs on surfaces carrying no $\mathrm{R}$ subunits or on surfaces carrying RI subunits, after determining that type I regulatory subunit isoforms (RI $\alpha$ and $\mathrm{RI} \beta)$ do not bind. Association and dissociation rates were determined from analyte dilution series (compare Fig. $3 B$ ). Kinetic constants were calculated by nonlinear regression of data using the Biaevaluation software, version 2.1 or 3.0 (Biacore). Equilibrium binding constants $\left(K_{\mathrm{d}}\right)$ were calculated from the respective rate constants on the basis of a Langmuir 1:1 binding model. To analyze competition between neurobeachin region $B$ and the synthetic 22-residue peptide DLIEEAASRIVDAVIEQVKAAY (gift of K. Tasken), which corresponds to residues 493-513 of the human thyroid AKAP, Ht31 (Carr et al., 1992), $1 \mu \mathrm{M}$ region $\mathrm{B}$ polypeptide was mixed with a concentration series of peptide Ht31(493-513) before injection. A dose-response curve was compiled from SPR response values 3 min after injection and fitted with the Prism software package (GraphPad). See also Herberg et al. (2000) for further technical information and binding behavior of other AKAPs to R subunit isoforms.

\section{RESULTS}

\section{Identification and primary structure of neurobeachin, a BEACH-WD40 domain protein}

To identify new proteins of neuronal synapses, a chicken brain cDNA expression library in $\lambda$ gt11 was immunoscreened with a serum raised against synaptic plasma membranes (Lichte et al., 1992). One of the immunopositive clones hybridized to an almost brain-specifically expressed mRNA in Northern blot analysis (see Fig. $5 A$ ). By several rounds of plaque hybridization rescreening beginning with this chicken cDNA as a probe, a mouse cDNA contig of $10949 \mathrm{nts}$ encompassing a complete reading frame was established. The putative start codon is preceded by $466 \mathrm{nts}$ of GC-rich 5'-untranslated sequence with several in-frame stop codons, and the end of the reading frame is followed by $1675 \mathrm{nts}$ of a 3 '-untranslated sequence with multiple in-frame stop codons but no poly(A) tail. The mouse cDNA encodes a polypeptide of 2936 amino acids $(327 \mathrm{kDa})$ that is moderately acidic ( $\mathrm{pI} 6.0)$ and has a high percentage of hydrophobic (38\%) and aromatic $(7.7 \%)$ amino acids.

The C-terminal region of this protein, which we name neurobeachin, contains a BEACH domain (Figs. 1, 2). The BEACH domain has been defined as a sequence motif of $\sim 280$ amino acids that the LYST gene product, mutated in the beige mouse and human Chediak-Higashi syndrome, shared with several anonymous sequences in the database (Nagle et al., 1996). It is present in multiple gene products and is evolutionarily ancient. In a database screen, we found 10 distinct BEACH sequences from mammalian sources (human and/or mouse), 6 from Caenorhabditis elegans, and 5 in the Drosophila genome. BEACH sequences are also found in fish (Fugu), plants (Arabidopsis), slime molds (Dictyostelium), and yeasts (Saccharomyces cerevisiae and Schizosaccharomyces pombe).

$\mathrm{BEACH}$ domain proteins have a common overall architecture (Fig. 1). In all 10 sufficiently long sequences currently available (5 distinct mammalian molecules and 1 each from fly, worm, plant, slime mold, and yeast), BEACH domains are followed by a WD40 repeat and then by the $\mathrm{C}$ terminus of the polypeptide. Upstream of the BEACH domain, the sequences of most proteins containing this sequence module are unrelated. Among these are the only three BEACH proteins about which any functional information is available: mammalian LYST and FAN and protozoan LvsA. The LYST gene product is involved in the biogenesis of lysosomes and lysosome-related secretory granules (Burkhardt et al., 1993; Nagle et al., 1996; Perou et al., 1996, 1997; Dell'Angelica et al., 2000). LvsA is implicated in the plasma membrane dynamics of Dictyostelium cell division (Kwak et al., 1999). FAN is a signal transduction protein that interacts with the cytoplasmic domain of the 55 $\mathrm{kDa}$ tumor necrosis factor receptor (Adam-Klages et al., 1996). YCS2, the only yeast gene product with a BEACH domain, is functionally uncharacterized. A mammalian gene product named BGL aligns with neurobeachin and shares its domain organization over its entire length and may therefore represent an isoform. The BGL sequence, apparently incomplete at the $\mathrm{N}$ terminus, was found in a genetic study (Feuchter et al., 1992), and no biochemical or other functional information on this protein is available. 


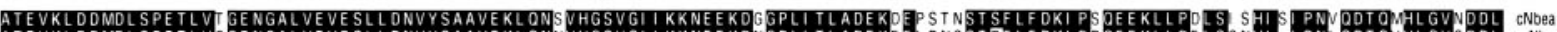

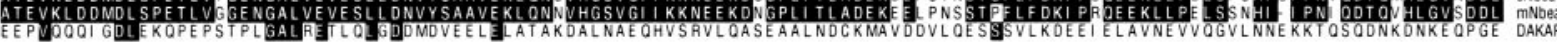

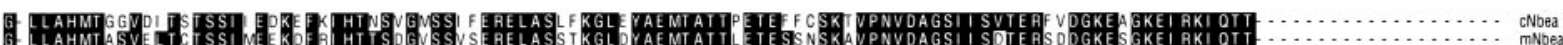

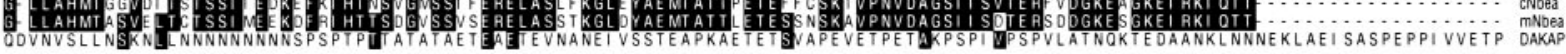

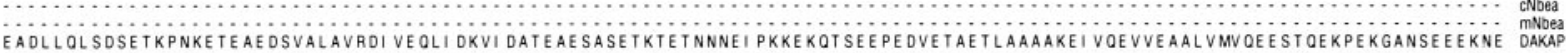
a.m.

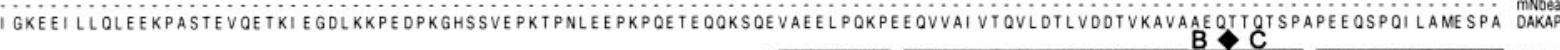

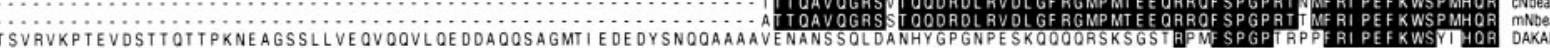

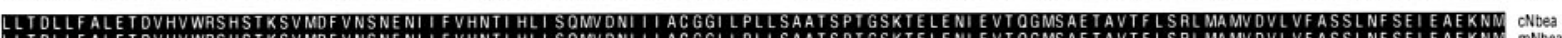

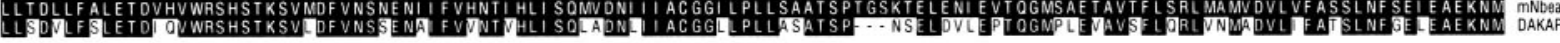

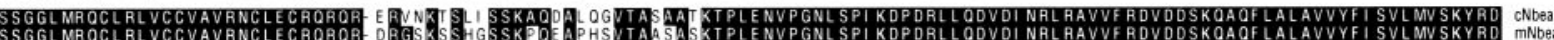

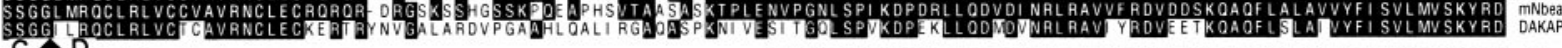

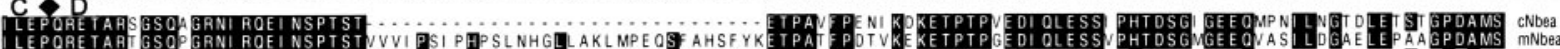

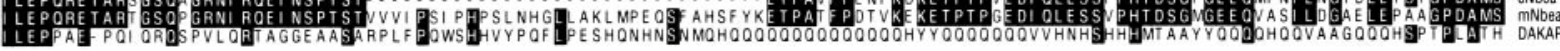

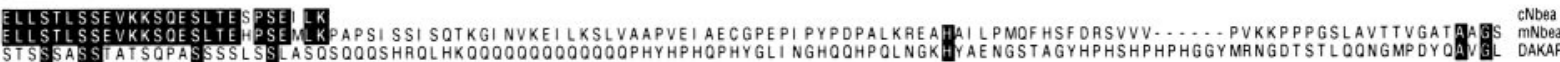

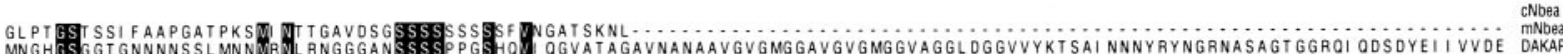

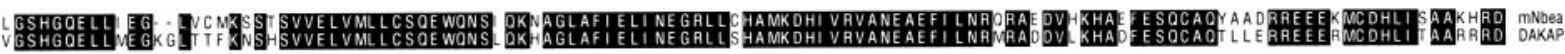

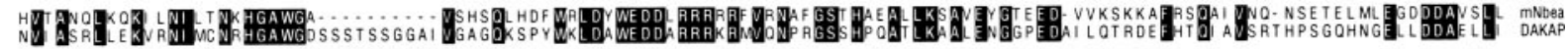

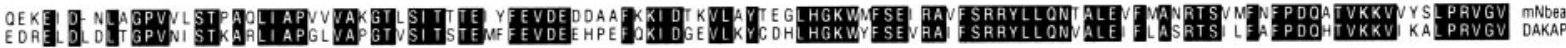
$E \bullet F$

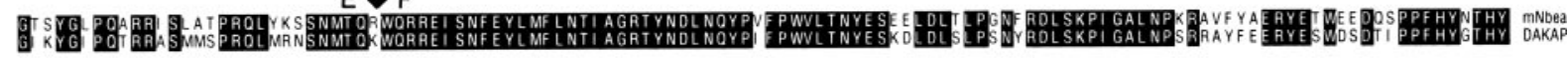

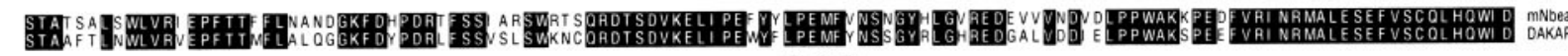

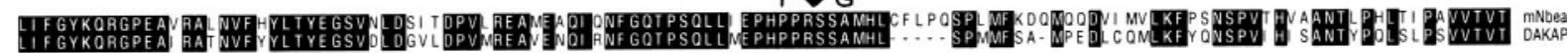

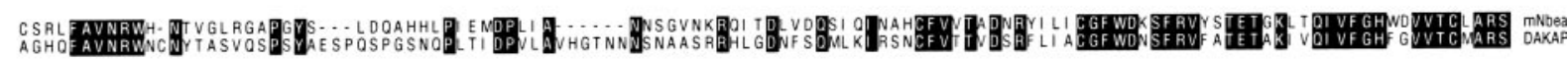

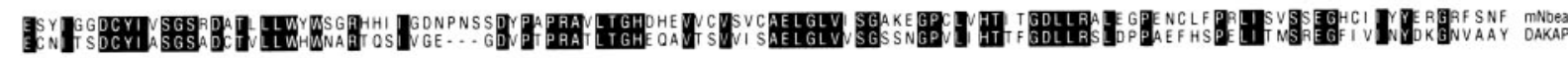

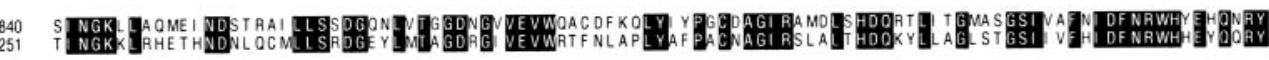



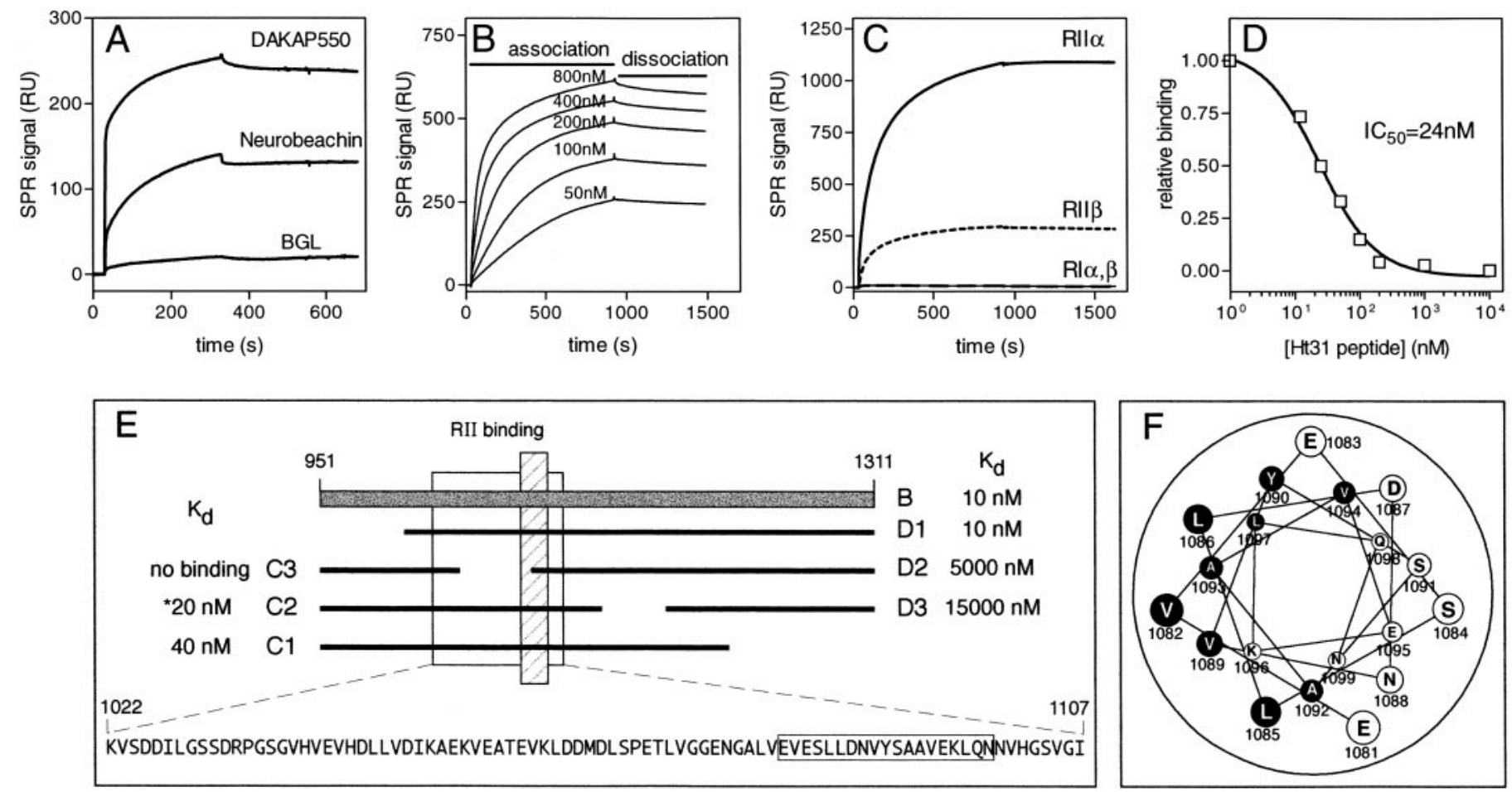

Figure 3. Protein kinase A regulatory subunit binding to neurobeachin measured by surface plasmon resonance (SPR). $A$, RII $\alpha$ binds to regions B of neurobeachin and DAKAP550 but not BGL (analyte concentrations, $1.5 \mu \mathrm{M}$ each). $B$, SPR tracings of a concentration series of neurobeachin region B binding to RII $\alpha$ performed for $K_{\mathrm{d}}$ determination. $C$, Neurobeachin region B binds RII $\alpha$ and RII $\beta$ but not RI $\alpha$ or RI $\beta$ (analyte concentration, $1.5 \mu \mathrm{M}$ ). $D$, The RII binding peptide from AKAP Ht31 competes with neurobeachin region B for RII $\alpha$ binding (neurobeachin region B concentration, $1 \mu \mathrm{M}$ ). $E$, Dissection of neurobeachin region B to delineate the RII binding sequence. Region B comprises amino acids 951-1311. Constructs C1-C3 reach from amino acid 951 to 1225,1133 , and 1041, respectively. Constructs D1-D3 extend from amino acids 1005 , 1088, and 1177 , respectively, to 1311 . $K_{\mathrm{d}}$ values were determined for these constructs by measuring concentration series as in part B and are indicated beside the constructs. As described in Materials and Methods, construct C2 (asterisk) displayed high-affinity binding only if prepared under nondenaturing conditions. D2 and D3 binding were very weak, with approximate $K_{\mathrm{d}}$ values of 5 and $15 \mu \mathrm{M}$, respectively, and no binding was detectable with C3 (detection limit, $20 \mu \mathrm{M}$ ). An open frame indicates the sequence region in which the high-affinity RII binding property resides (amino acids 1022-1107). Because known RII binding sites are $\sim 20$ amino acids long, we assume that if the binding site in region B should overlap with the end of a nonbinding construct, C3 or D2, it will do so for a maximum of 20 residues. The candidate core RII binding sequence (amino acids 1081-1099) with high $\alpha$-helix potential is indicated by a hatched frame in the overview and an open box in the sequence at the bottom. F, Helical representation of amino acids 1081-1099 illustrating the highly amphiphilic nature of this structure. Filled circles symbolize hydrophobic residues, and open circles indicate hydrophilic amino acids.

Full-length neurobeachin homologs also exist in Drosophila (DAKAP550) and C. elegans (CEF10F2.1) (Fig. 1).

Comparison of the neurobeachin sequence with its full-length and partial homologs defines regions of high or low sequence similarity (Fig. 1). The BEACH domain is highly conserved between all these proteins. In the WD40 regions, sequence similarity of neurobeachin is high to BGL, moderate to DAKAP550 and CEF10F2.1, but very low in comparison with LYST, FAN, LvsA, and YCS2 such that only the overall WD40 architecture is conserved between the partial homologs. Regions B and D (corresponding to amino acids 951-1311 and 1576-1872, respectively, of mouse neurobeachin) diverge in sequence or length among neurobeachin, BGL, DAKAP550, and CEF10F2.1. These two regions of neurobeachin have a distinctively lower percentage of hydrophobic amino acid residues (27-28\%) than the other regions (36$43 \%$ ). Between mouse and chicken neurobeachin, sequence similarity is very high ( $88 \%$ amino acid identity) also in regions B and D where neurobeachin and BGL diverge (Fig. 2), and several human ESTs in the sequence database have 100\% amino acid sequence identity with mouse neurobeachin, including sequences in region $\mathrm{B}$. This indicates very high phylogenetic sequence conservation of neurobeachin in vertebrates, and that mouse neurobeachin and human BGL are no species orthologs but distinct gene products. Moreover, the human neurobeachin $(N B E A)$ and BGL genes have been mapped to different chromosomes [NBEA: chromosome 13q13 (Gilbert et al., 1999); BGL: chromosome 4q31 (The National Center for Biotechnology Information Human Gene Map)].

Sequence heterogeneity, probably attributable to differential
mRNA splicing, was observed at four sites (Figs. 1, 2). Amino acids 1601-1632 (VVV... FYK) of mouse neurobeachin have no counterparts in chicken neurobeachin or in human BGL, but predominate in 30-d-old mouse brain mRNA ( $>90 \%$; only the long variant is detectable by RT-PCR and sequencing). Codons 1402-1404 (GSK) are deleted in $\sim 50 \%$ of mouse neurobeachin mRNAs, codons 1826-1831 (MINTTG) are deleted in $\sim 25 \%$, and codons 2560-2564 (CFLPQ) are deleted in $\sim 25 \%$ of the mRNA population, as determined by sequencing of multiple cDNA and RT-PCR subclones. GSK and CFLPQ are also missing in the available BGL, DAKAP550, and CEF10F2.1 sequences within otherwise highly conserved contexts. CFLPQ is located at the hinge between the $\mathrm{BEACH}$ and WD40 domains.

\section{Neurobeachin, but not its putative isoform BGL, is an AKAP}

We found neurobeachin and BGL to be colinear with a partial cDNA from Drosophila, DAKAP550 (Han et al., 1997), with sequence similarity in regions $\mathrm{A}$ and $\mathrm{C}$ but not in $\mathrm{B}$ and $\mathrm{D}$. We have completed the C-terminal DAKAP550 sequence, showing that DAKAP550 is a full-length homolog of neurobeachin and BGL (Figs. 1, 2). The DAKAP550 sequence is slightly more related to neurobeachin than to BGL [56\% identity with neurobeachin in the $\mathrm{C}$-terminal part of region $\mathrm{A}, 63 \%$ in region $\mathrm{C}, 59 \%$ in region $\mathrm{E}$, $78 \%$ in region $\mathrm{F}$, and $44 \%$ in region $\mathrm{G}$, and low similarity at the beginning of region $\mathrm{B}$, as opposed to $52 \%(\mathrm{~A}), 61 \%(\mathrm{C}), 55 \%(\mathrm{E})$, $76 \%(\mathrm{~F})$, and $45 \%(\mathrm{G})$ identity with BGL].

Two binding sites for the RII of PKA were identified by Han et al. (1997) in region B of DAKAP550. Neither these sites nor other 


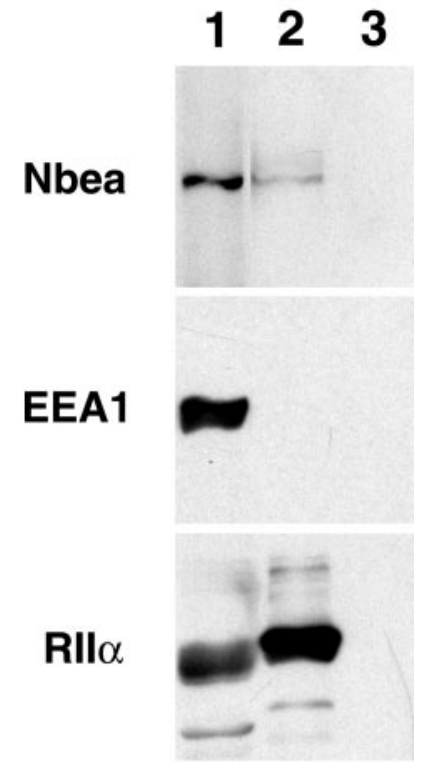

Figure 4. cAMP-agarose coprecipitates neurobeachin with RII from rat brain cytosol. Immunoblots were developed with antibodies against neurobeachin (Nbea), EEA1 (negative control), and $R I I \alpha$ as indicated: cytosol, lane 1; cAMP-agarose beads after incubation in cytosol without (lane 2) or with (lane 3) $10 \mathrm{~mm}$ competitor cAMP. $\gamma$-Adaptin as a second negative control (data not shown) gave the same result as EEA1. The RII $\alpha$ band of the cytosol sample is displaced downward by the thick, unlabeled tubulin band migrating above it.

parts of DAKAP550 region B have sequence similarity to region B sequences of neurobeachin or BGL. However, the similarity of domain organization prompted us to investigate RII binding to regions $\mathrm{B}$ of neurobeachin and BGL. The RII binding sites of most established AKAPs do not share sequence similarity. Their common feature is the propensity to form an amphiphilic $\alpha$-helix (Carr et al., 1992; Nauert et al., 1996; Han et al., 1997; Fraser et al., 1998; Gray et al., 1998; Colledge and Scott, 1999).

Domains B of mouse neurobeachin and human BGL, and a region of similar size $(\sim 350$ amino acids $)$ centered around the RII binding sites of Drosophila DAKAP550 as a positive control, were amplified by RT-PCR and subcloned into a His-tag expression vector. The interaction of the recombinant proteins with recombinant bovine RII $\alpha$ was analyzed by SPR (Fig. 3). We found that domain B of neurobeachin binds RII $\alpha$ with high affinity $\left(K_{\mathrm{d}}, 10 \mathrm{nM}\right)$ and slow dissociation kinetics, in a fashion very similar to the Drosophila molecule, in which the affinity for RII $\alpha$ is higher yet $\left(K_{\mathrm{d}}\right.$, $2 \mathrm{nM}$ ). In contrast, no significant RII binding could be detected with domain $\mathrm{B}$ of BGL (Fig. $3 A, B$ ). Neurobeachin region B binds only the RII isoforms, preferring $\operatorname{RII} \alpha\left(K_{\mathrm{d}}, 10 \mathrm{nM}\right)$ slightly over $\mathrm{RII} \beta$ $\left(K_{\mathrm{d}}, 30 \mathrm{nM}\right)$, whereas no detectable binding was found with RI $\alpha$ and RI $\beta$ (Fig. 3C). A synthetic 22-residue peptide, Ht31(493-513), derived from the RII binding site of the human thyroid AKAP, Ht31 (Carr et al., 1992), efficiently competed with neurobeachin region $\mathrm{B}$ for RII binding, with an $\mathrm{IC}_{50}$ of $24 \mathrm{~nm}$ at a region $\mathrm{B}$ concentration of $1 \mu \mathrm{M}$ (Fig. 3D). This indicates that the same site on RII $\alpha$ binds Ht31 and neurobeachin and is additional evidence for the specificity of the RII-neurobeachin interaction. Binding measurements with a series of deletion constructs delineated the RII binding site of neurobeachin region $\mathrm{B}$ to an interval between amino acids $\sim 1022-1107$ (Fig. 3E). This interval contains a sequence with a high potential to form an amphiphilic $\alpha$-helix (amino acids 1081-1099) (Fig. 3F) that is a good candidate for the core binding site.

From rat brain cytosol, neurobeachin could be coprecipitated with RII $\alpha$ by cAMP-agarose, suggesting the existence of a complex of both native proteins. Pulldown of both proteins was blocked by an excess of free cAMP (Fig. 4).

\section{A neurobeachin mRNA}

FB C M Li A Te O Sp H Lu Pa

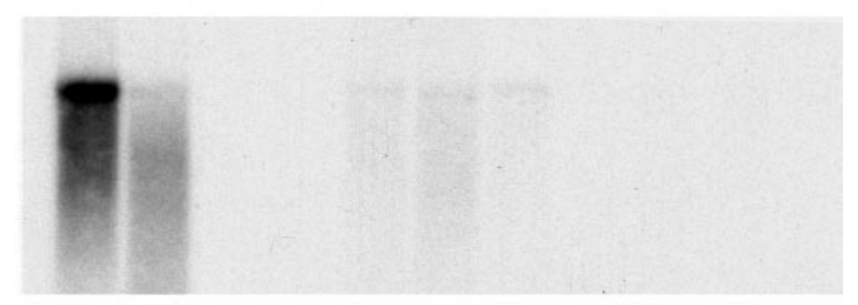

B neurobeachin protein

\section{BS FB C A K M H Te Li Lu Pa St I}

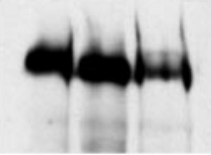

Figure 5. Brain-specific expression of neurobeachin. $A$, Chicken neurobeachin mRNA [10 $\mu \mathrm{g}$ poly $\left(\mathrm{A}^{+}\right)$RNA per lane]. $B$, Mouse neurobeachin protein $(50 \mu \mathrm{g}$ protein of tissue homogenate per lane). Tissue abbreviations are as follows: $A$, adrenal gland; $B$, brain; $B S$, brain stem; $C$, cerebellum; $F B$, forebrain; $H$, heart; $I$, small intestine; $K$, kidney; $L i$, liver; $L u$, lung; $M$, muscle; $O$, ovary; $P a$, pancreas; $S p$, spleen; $S t$, stomach; Te, testis. Smears and minor bands below the main bands are attributed to partial degradation of these very long mRNA and protein molecules.

\section{Neurobeachin is a brain-specific protein}

A Northern blot with mRNAs from several chicken tissues was hybridized with the chicken neurobeachin cDNA, 10.2 (Fig. 5A). A large mRNA of $\sim 12$ kilonucleotides hybridized with high intensity in forebrain and cerebellum, hybridized weakly in the endocrine tissues, adrenal gland, testis, and ovary, was barely detectable on longer exposures of the blot in heart and lung, and was undetectable in skeletal muscle, liver, spleen, and pancreas.

Analysis of the National Center for Biotechnology Information UniGene database showed that, in good agreement with the chicken Northern blot, most ESTs representing human neurobeachin (UniGene cluster Hs.3821) are from neuronal and endocrine tissues. Among 11 neurobeachin cDNAs from tissuespecific libraries, 7 are from brain and 1 each from retina, germ cell, testis, and kidney. In contrast, human BGL ESTs (UniGene cluster Hs.62354) come from a large variety of tissues but few from brain (56 cDNAs: one each from brain and retina, others from liver, spleen, colon, ear, germ cell, heart, kidney, lung, lymph node, pancreas, parathyroid, placenta, prostate, skin, stomach, testis, uterus, whole blood).

To determine the tissue specificity of neurobeachin at the protein level, a Western blot of homogenates from various mouse tissues was probed with an affinity-purified antibody that had been raised against recombinant neurobeachin region $\mathrm{B}$ (Fig. 5B). A strong protein band of molecular size far above the $206 \mathrm{kDa}$ standard was detectable only in brain lysates, with similar intensities in forebrain, cerebellum, and brainstem; a very faint band was seen in stomach. This band could be specifically immunoprecipitated from brain lysate, and its labeling is blocked by preincubation of the antibody with neurobeachin region $\mathrm{B}$ but not by BGL region B (data not shown). Thus, Western blot analysis of mouse tissues indicates a highly brain-selective expression of neurobeachin protein. The low mRNA levels in endocrine tissues seen by Northern blot analysis may not be translated into protein.

During mouse postnatal brain development, neurobeachin mRNA abundance is highest in neonatal brain and declines to 

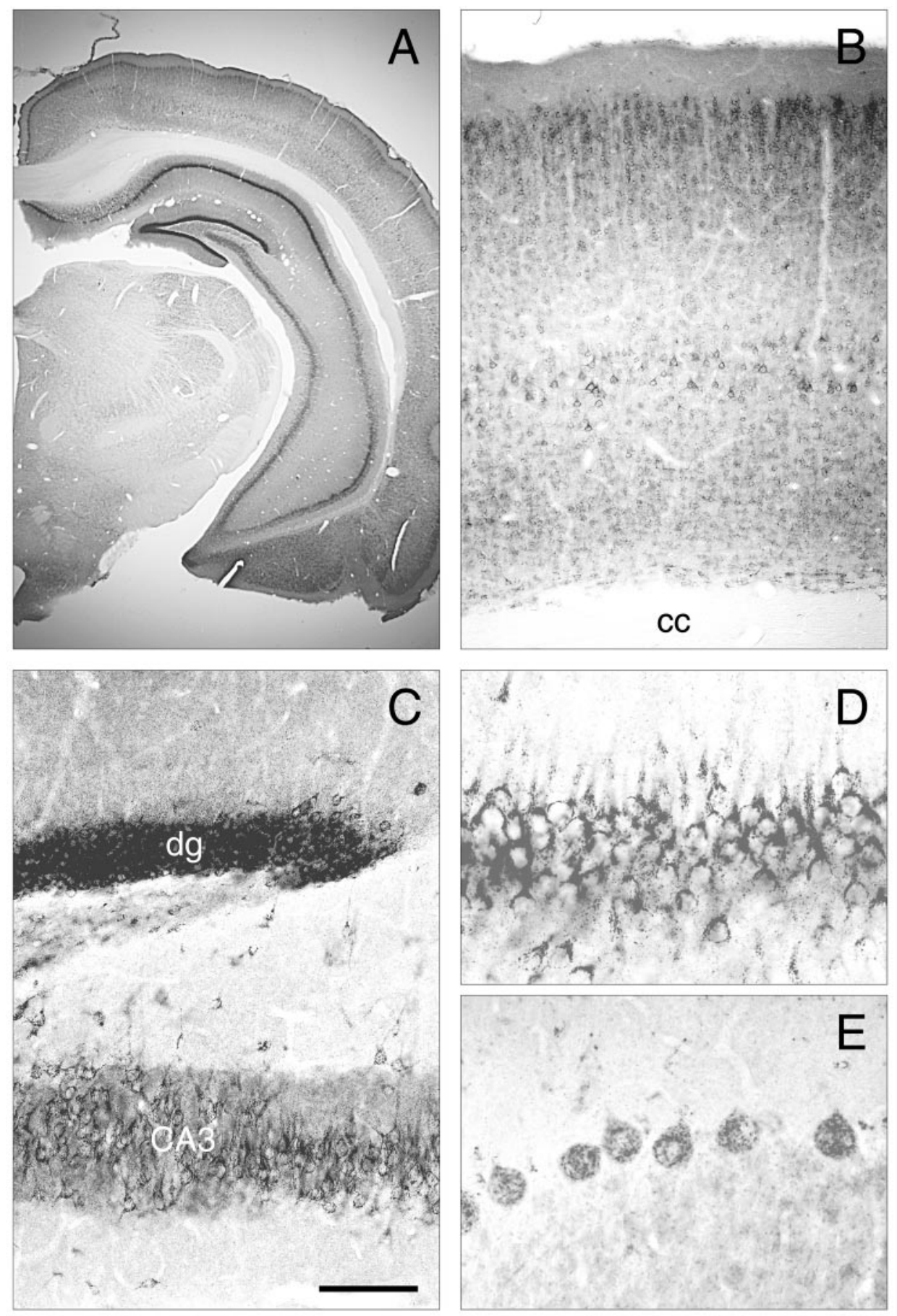

Figure 6. Immunocytochemical localization of neurobeachin in rat brain at the lightmicroscopical level. $A$, Survey photomicrograph of a frontal $50 \mu \mathrm{m}$ vibratome section exhibits intense staining of perikarya-rich areas, moderate staining of neuropil-rich areas, and weak staining of myelin-rich areas. Views from the parietal cortex $(B)$ and the hippocampal formation $(C)$ illustrate that many different neuronal populations are immunopositive for neurobeachin ( $c c$, corpus callosum; $d g$, granule cell layer of the dentate gyrus). Note the differential staining of different neuropil-rich areas in $C$. Views at high magnification from the CA1 area of the hippocampus $(D)$ and the Purkinje cell layer of the cerebellum $(E)$ show the coarsely granular subcellular pattern of neurobeachin in cell bodies at the light microscopical level. Scale bar (shown in $C$ ): $A, 1.8 \mathrm{~mm}$; $B, 210 \mu \mathrm{m} ; C, 250 \mu \mathrm{m} ; D, 50 \mu \mathrm{m} ; E, 55 \mu \mathrm{m}$. reach adult levels ( $\sim 50 \%$ of neonatal) at postnatal day 25 . Neurobeachin mRNA expression in NS20Y neuroblastoma cells is not affected within $24 \mathrm{hr}$ by raising the intracellular cAMP level through treatment with forskolin/IBMX (data not shown).

\section{Neurobeachin is associated with tubulovesicular neuronal endomembranes near the trans-Golgi and throughout the cell}

Immunoperoxidase staining of rat brain sections prominently visualizes the cell bodies and thick processes of many neuronal populations throughout the brain (Fig. 6). In light microscopy, immunoreaction product typically appears as coarse granules in the cytoplasm of neurons and their proximal dendrites, whereas the nuclei are spared (Fig. 6D,E). Neuropil-rich regions are stained in a diffuse or finely grained fashion, whereas myelin-rich regions are poorly stained or unstained.
In electron microscopy, neurobeachin immunoreaction product decorates the cytosolic faces of vesicular and tubular intracellular membranes, often in clusters (Fig. 7A). Neurobeachin-positive vesicle clusters are often adjacent to the ends and the concave faces, i.e., the trans sides, of Golgi stacks (Fig. 7B). Also the dilated ends of Golgi cisternae are sometimes decorated (Fig. 7C). Occasionally, extensive neurobeachin-positive endomembrane fields were observed (Fig. 7D). Neurobeachin immunoreactivity was also seen on buds of the plasma membrane (Fig. $7 A$, arrows). In the neuronal periphery, patches of immunoreaction product were found throughout thick and thin processes, at some postsynaptic sites, and, rarely, presynaptically (data not shown). These characteristic immunoperoxidase staining patterns in light and electron microscopy were seen with two different affinity-purified sera against region $\mathrm{B}$. They were not observed if the antibodies were incubated 


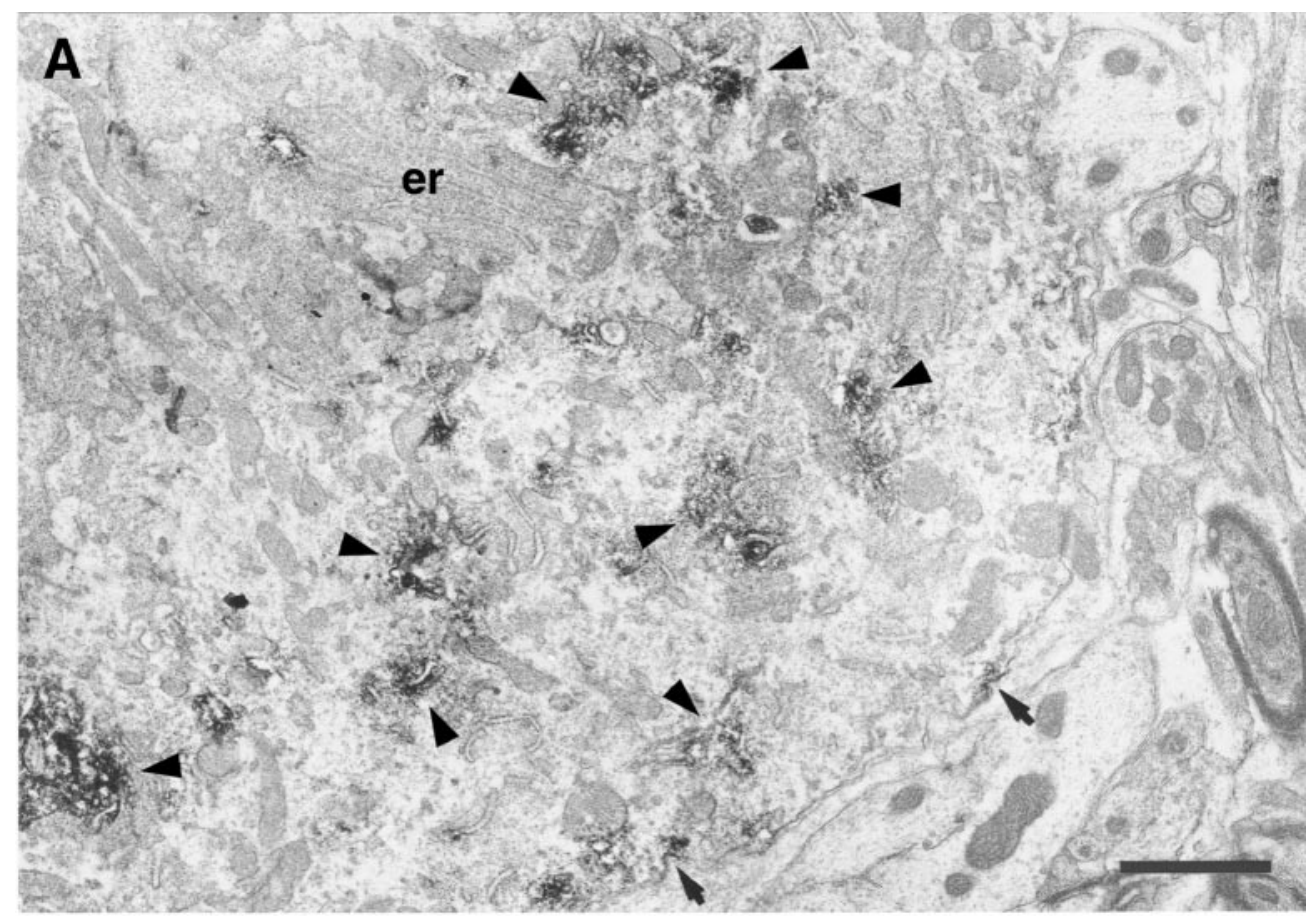

Figure 7. Immunoperoxidase electron microscopy of neurobeachin-positive subcellular structures in rat brain neurons. $A$, The electron-dense neurobeachin immunoreaction product decorates polymorphic tubulovesicular endomembranes (arrowheads) and plasma membrane buds (arrows) of a cerebellar Purkinje cell. B, Neurobeachin immunolabeling of a vesicle cluster next to the concave face of a Golgi stack (arrowhead) in a Purkinje cell body. A multivesicular body $(\mathrm{mb})$ is immunonegative, as generally observed. $C$, Labeling of the dilated ends of Golgi-like membrane cisternae in a pyramidal neuron of the hippocampus. $D$, An extensive field of immunopositive tubulovesicular endomembranes surrounded by several Golgi stacks (arrows) in a Purkinje cell. er, Endoplasmic reticulum; $n$, nucleus. Scale bar (shown in $A$ ): $A, 1 \mu \mathrm{m} ; B, 0.6 \mu \mathrm{m} ; C$, $0.5 \mu \mathrm{m} ; D, 0.8 \mu \mathrm{m}$.
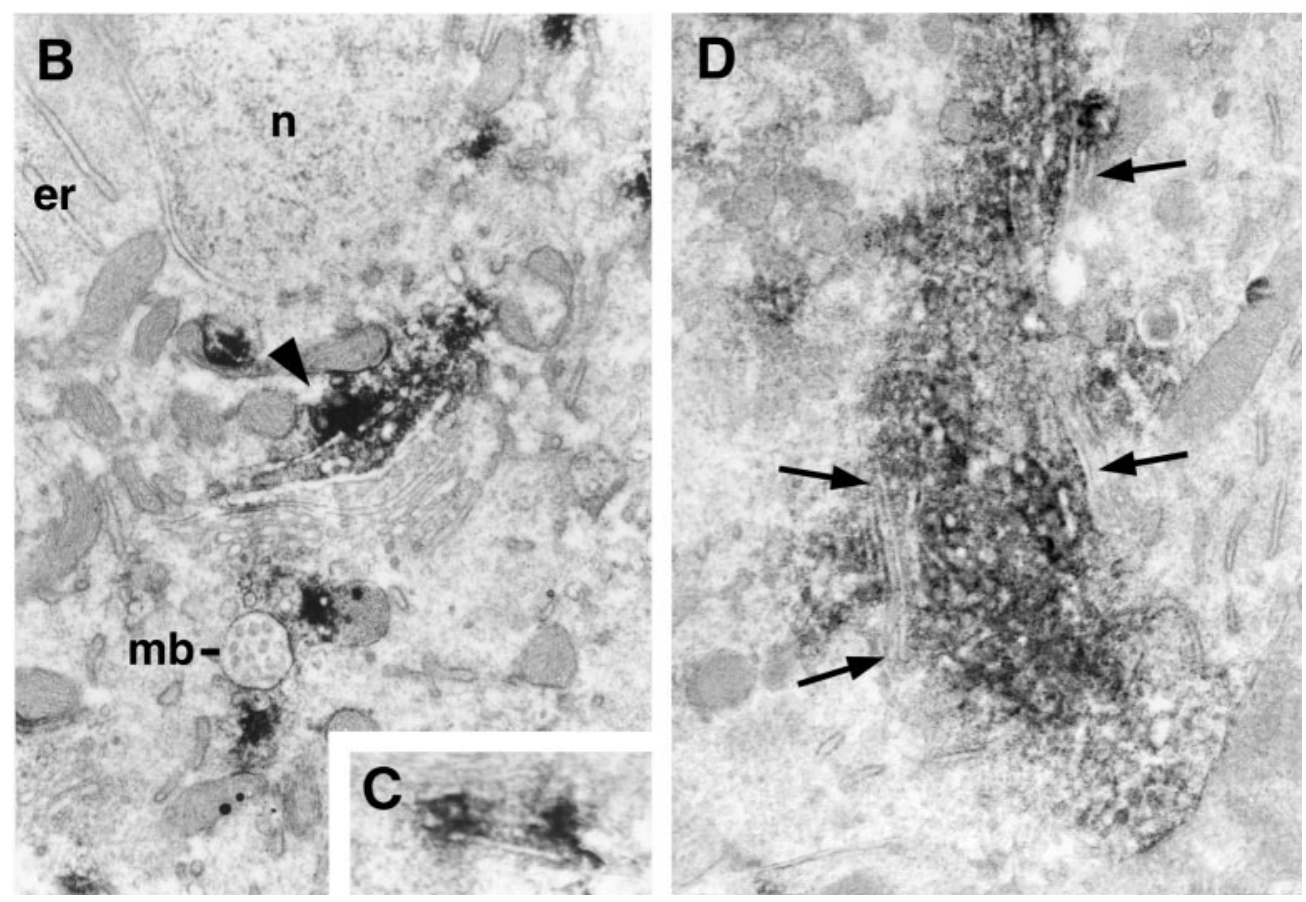

with an excess of the recombinant antigen or if preimmune antibodies were used as negative controls.

By pre-embedding immunogold electron microscopy of the cerebellum, the subcellular localization of neurobeachin was investigated at higher resolution. Association with pleomorphic tubular and vesicular membranes near the trans sides of Golgi complexes and throughout neuronal cell bodies could be confirmed (Fig. $8 A, B)$. If Golgi stacks were sectioned such that convex (cis) and concave (trans) faces could be discerned, labeling was clearly concentrated at the concave sides. In $n=13$ stacks analyzed, $89 \%$ of the gold particles were localized over the concave halves and $11 \%$ over the convex halves. In cell processes, gold particles were typically associated with small tubulovesicular structures (Fig. 8D). Circumscript decoration of postsynaptic plasma membranes was observed in a minority of synapses in the molecular layer $(1 \% ; n=$ 858 synapses inspected) and the granule cell layer $(5 \% ; n=412$ synapses). Symmetrical synapses between Golgi cell terminals and granule cell dendrites were among the immunopositive synapses in the granule cell layer (Fig. $8 C$ ), whereas synapses between mossy fiber terminals and granule cell dendrites were never labeled. Incubation with preimmune antibody served as negative control and resulted only in scattered single particles without a concentration at particular structures.

\section{Neurobeachin immunofluorescence puncta concentrate near the Golgi complex but do not colocalize with any of numerous endomembrane marker proteins}

Neurobeachin is detectable in NS20Y mouse neuroblastoma cells and PC12 rat neuroendocrine cells by both immunoblotting (data not shown) and immunofluorescence (Fig. 9). Immunofluorescence visualizes small puncta, which are densest around the nucleus where they often form clusters or strings but also scatter 

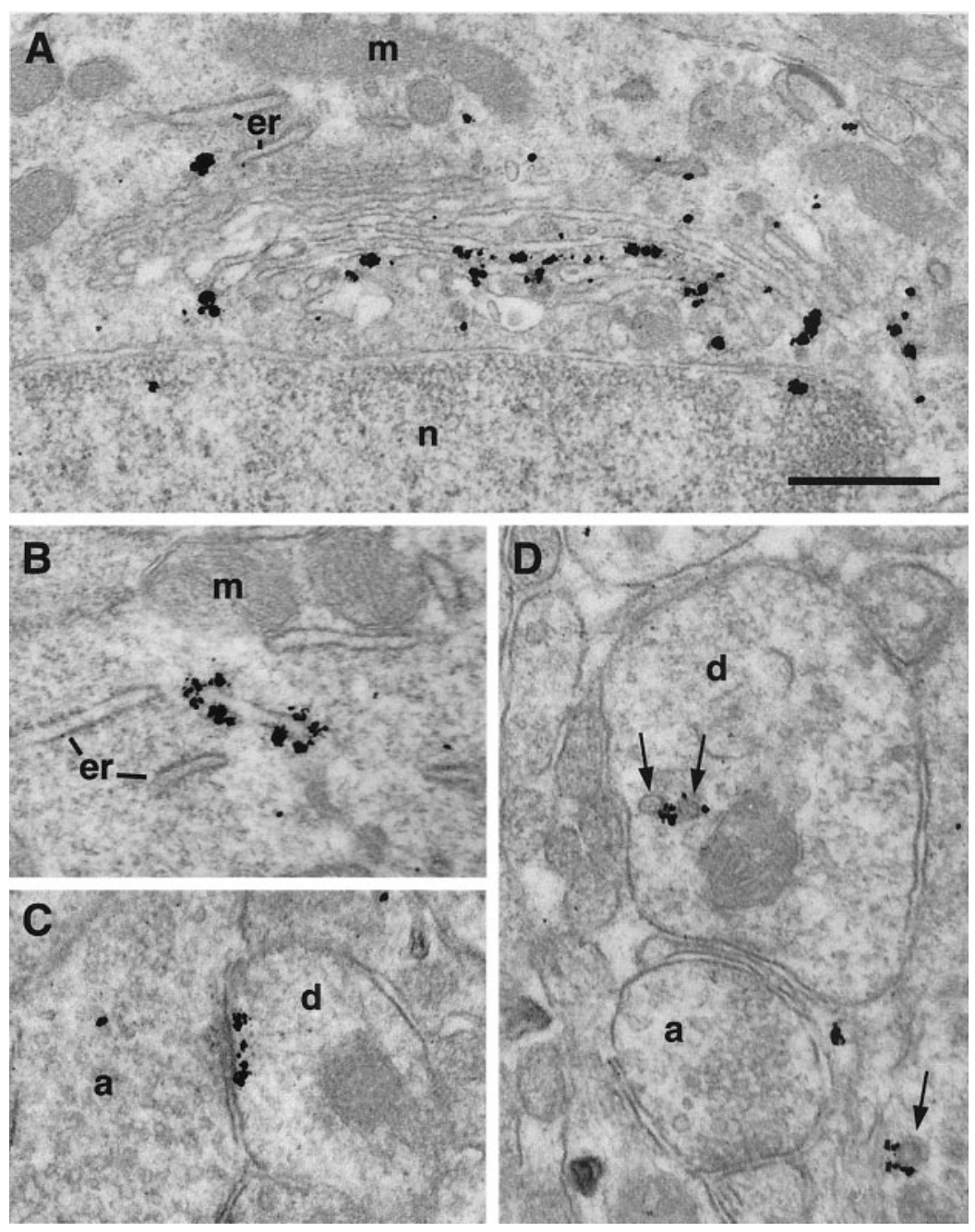

Figure 8. Pre-embedding immunogold electron microscopy of neurobeachin-positive endomembranes in rat cerebellar neurons. $A$, Immunolabeling concentrating at the concave side of a Golgi stack in the cell body of an unidentified neuron in the molecular layer. $B$, Labeling of the dilated ends of an unidentified endomembrane tubule or cisterna in a Purkinje cell body. $C$, Labeling of the postsynaptic membrane of a granule cell dendrite in contact with a Golgi cell axon terminal. $D$, Labeling of small vesicle or tubule cross sections (arrows) in unidentified cell processes in the granule cell layer. $a$, Axon terminal; $d$, dendrite; er, endoplasmic reticulum; $m$, mitochondrion; $n$, nucleus. Scale bar (shown in $A$ ): $A$, $0.50 \mu \mathrm{m} ; B, 0.37 \mu \mathrm{m} ; C, 0.26 \mu \mathrm{m} ; D, 0.27 \mu \mathrm{m}$. throughout the cytoplasm. Diff use immunolabeling is additionally observed.

By double-immunofluorescence microscopy of PC12 cells with various marker antibodies, we explored the membrane compartment(s) with which neurobeachin is apparently associated (most data not shown; see Fig. 9 for examples). Clearly different patterns of no notable overlap with neurobeachin were produced by antibodies against Lamp-1 (lysosomes), rab7, and the cationindependent $300 \mathrm{kDa}$ mannose-6-phosphate receptor (late endosomes), transferrin receptor (recycling endosomes), EEA1 (early endosomes), PDI (endoplasmic reticulum), and synaptophysin (synaptic-like microvesicles), and with Mitotracker (mitochondria). Patterns qualitatively similar to neurobeachin but without notable overlap of puncta were obtained for secretogranin II (secretory granules), rab1A [ER-Golgi intermediate compartment (ERGIC)], Rab4, synaptobrevin 2, and cellubrevin (early endosomes and transport vesicles). The coat proteins involved in the generation of transport vesicles at the trans-Golgi network (TGN), clathrin heavy chain, $\gamma$-adaptin (AP-1), $\delta$-adaptin (AP-3), and $\beta$-NAP/ $\beta 3 \mathrm{~B}$ adaptin (a neuron-specific AP-3 subunit isoform) also gave patterns qualitatively similar to, but little or no clear overlap of, individual puncta with neurobeachin. The markers $\beta$-COP (transport vesicles of the Golgi complex and ERGIC), KDEL receptor (ERGIC and cis-Golgi), mannosidase II (Golgi complex), and TGN38 (TGN) labeled broad perinuclear ribbons. Neurobeachin-positive perinuclear clusters and strings were sparser than the gross Golgi or TGN structures labeled by these markers, lying within or immediately adjacent to them (Fig. 9). Conversely, in the cell periphery, puncta positive for $\beta$-COP, KDEL receptor, mannosidase II, and TGN38 were much sparser than neurobeachin-positive puncta and did not overlap with them. In conclusion, none of the markers tested displayed significant colocalization with neurobeachin, particularly not in the cell periphery. Very close proximity or partial overlap, within the resolution of light microscopy, was seen between perinuclear neurobeachin clusters and proteins of the Golgi complex or adjacent structures, notably with $\beta$-COP, KDEL receptor, mannosidase II, and TGN38.

Perinuclear neurobeachin also follows Golgi rearrangement induced by aluminum fluoride. In untreated PC12 cells, microtubules were seen by immunofluorescence to tangentially surround the nucleus in a symmetrical way. $\mathrm{AlF}_{4}{ }^{-}$treatment for 30 min caused their rearrangement to a polarized pattern that converged presumably on the microtubule-organizing center (MTOC) (data not shown). Concurrently, the markers $\beta$-COP (data not shown) and KDEL receptor (Fig. $9 A$ ) concentrated around the MTOC, and so did perinuclear neurobeachin (Fig. 9A). Under all conditions, neurobeachin-positive perinuclear structures were in close vicinity or partial overlap but sparser and not congruent with $\beta$-COPpositive and KDEL receptor-positive structures. In the cell periphery, neurobeachin-positive puncta were more numerous than and did not overlap with $\beta$-COP-positive and KDEL receptorpositive puncta (Fig. 9A). The $\mathrm{AlF}_{4}{ }^{-}$-induced redistribution of perinuclear neurobeachin toward the MTOC region, concurrent with the microtubule cytoskeleton and Golgi markers, suggests a physical or functional linkage between perinuclear neurobeachinpositive membranes and the Golgi complex or the microtubule cytoskeleton.

\section{Neurobeachin association with Golgi-near membranes is stimulated by GTP $\gamma$ S and dispersed by brefeldin A}

The proximity of a subpopulation of neurobeachin-positive endomembranes to the trans-Golgi/TGN suggested that neurobeachin 
A

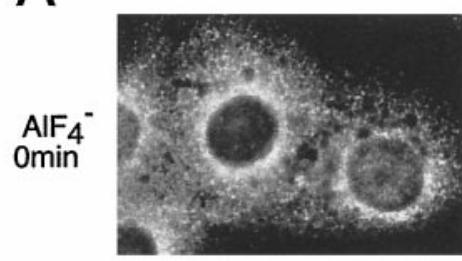

Neurobeachin

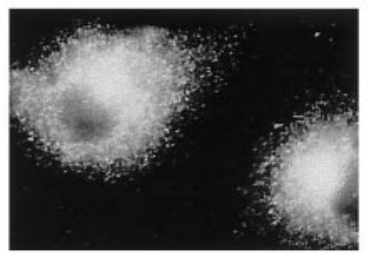

$\mathrm{AlF}_{4}$

30min

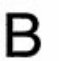

BFA

Omin

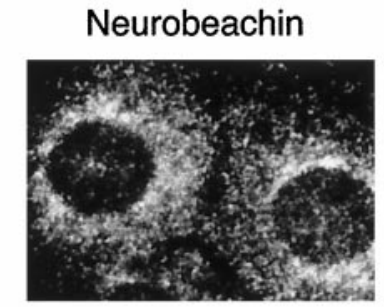

BFA
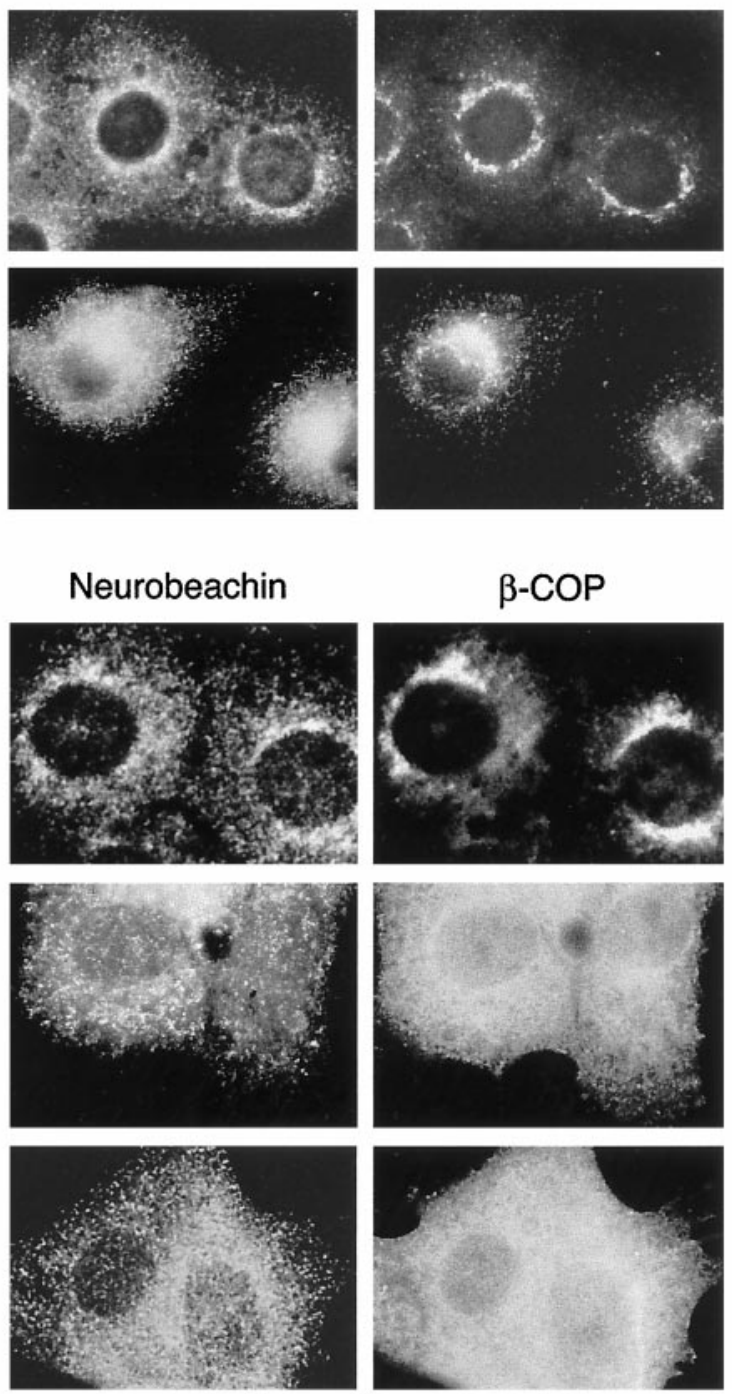

Man II
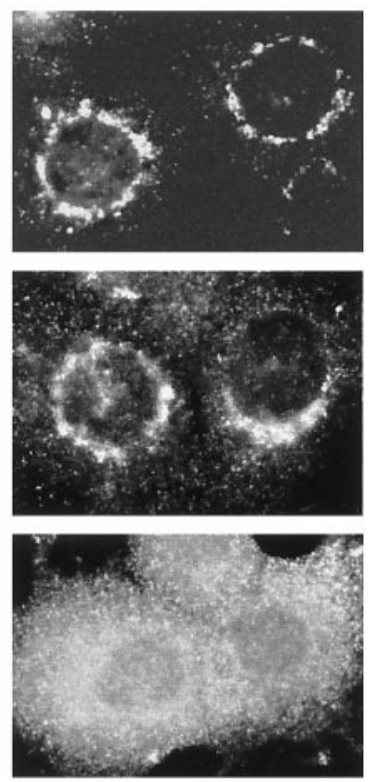

Figure 9. Punctate pattern of neurobeachin of $\mathrm{AlF}_{4}{ }^{-}$and BFA. $A, \mathrm{AlF}_{4}$ induces pericentrosomal clustering of perinuclear neurobeachin, concurrent with KDEL receptor $\beta$-COP (data not shown). $B$, BFA rapidly disperses punctate neurobeachin (left column) close to the nucleus but not in the cell periphery. $\beta$-COP (central column; corresponding double-immunofluorescence images) and mannosidase II (right column; representative images from a separate neurobeachin/mannosidase II double immunofluorescence) illustrate the different time courses of the dispersion, by BFA, of a coat protein versus an intrinsic Golgi membrane protein.

whereas they give little or no background signal with corresponding endogenous proteins of the acceptor cells (monkey COS-7 cells), either because they do not cross-react with the COS-7 proteins, because these cells do not express the particular protein (as in the case of neurobeachin), or because the endogenous protein is washed out after permeabilization. This allows the selective detection of newly recruited proteins.

Immunoblot analysis (Fig. 10) shows that neurobeachin recruitment is strongly enhanced by GTP $\gamma \mathrm{S}$ but antagonized by BFA. Moreover, GTP $\gamma \mathrm{S}$ added after BFA fails to stimulate recruitment, whereas BFA after GTP $\gamma \mathrm{S}$ cannot block recruitment, as demonstrated previously for $\gamma$-adaptin (AP-1) and $\mu 3$-adaptin (AP-3) recruitment (Robinson and Kreis, 1992; Simpson et al., 1996). This is in agreement with the current view of coat recruitment where BFA acts upstream of GTP by blocking GDP-to-GTP exchange on ARF (Springer et al., 1999). As positive controls in our experiment, both $\gamma$-adaptin (an AP-1 subunit) and $\beta$-NAP (a neuronspecific AP-3 subunit) show the same behavior. In contrast, as negative controls, neither the binding of exogenous RII $\alpha$ subunit nor of HSB [a novel cytosolic protein peripherally associated with membranes; Kutzleb et al. (1998)] to acceptor cells is stimulated by GTP $\gamma \mathrm{S}$ or inhibited by BFA (Fig. 10).

Double-immunofluorescence microscopy demonstrates that neurobeachin is primarily recruited to perinuclear ribbons that are also positive for acceptor cell giantin, an intrinsic Golgi protein (Fig. 11). Neurobeachin labels all giantin-positive ribbons and in addition, but more faintly, numerous giantin-negative patchy structures
Kreis, 1992; Seaman et al., 1993), antibodies detect proteins newly recruited from exogenous cytosol (prepared from rat brain), after BFA was washed out (data not shown).
Next, we could demonstrate that neurobeachin is recruited in vitro from cytosol to perinuclear endomembrane structures of freeze-permeabilized cells in a fashion stimulated by GTP $\gamma \mathrm{S}$ and
antagonized by BFA. In this experimental setup (Robinson and 


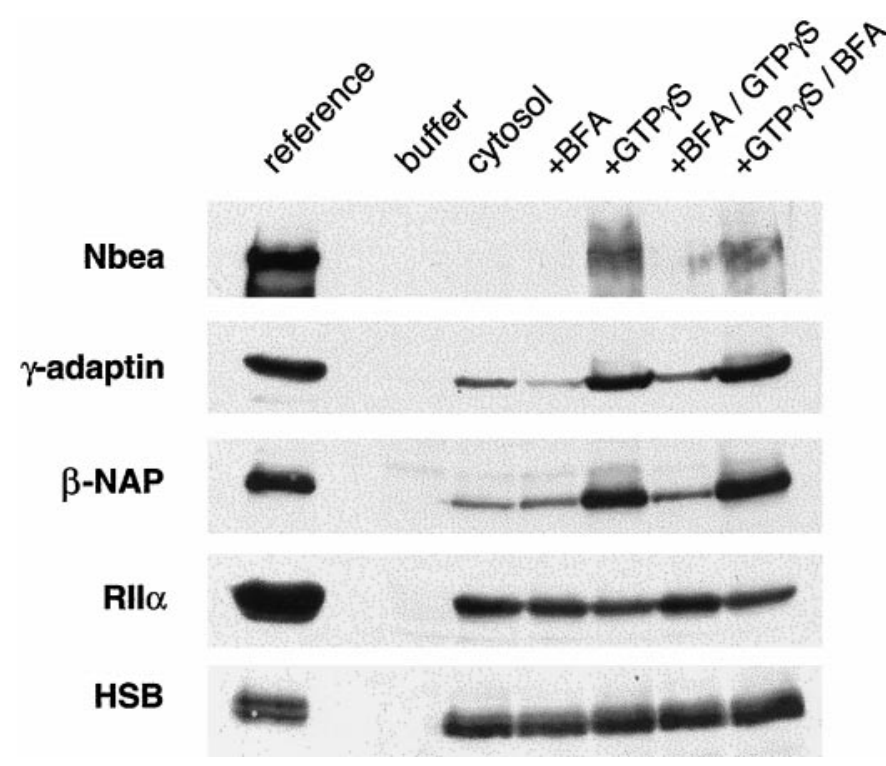

Figure 10. Recruitment of neurobeachin from cytosol to Golgi-near membranes is stimulated by GTP $\gamma \mathrm{S}$ and antagonized by BFA: immunoblot analysis. Freeze-permeabilized, washed COS-7 cells were incubated for 10 min with cytosol buffer only (buffer), with cytosol only (cytosol), or with cytosol supplemented either with $100 \mu \mathrm{g} / \mathrm{ml}$ BFA or with $0.5 \mathrm{~mm}$ GTP $\gamma$ S. For sequential drug treatments, the first 10 min incubation with either BFA or GTP $\gamma \mathrm{S}$ was followed by a second $10 \mathrm{~min}$ incubation with both reagents combined, all in cytosol. Cells were then washed and pelleted, and proteins bound to them were analyzed by immunoblotting. The first lane (reference) carries a reference aliquot of the cytosol.

all over the cell periphery. When inspected in fine detail (data not shown), giantin immunofluorescence forms continuous, sharpedged threads, whereas neurobeachin immunofluorescence forms ribbons composed of many small puncta that lie over and immediately beside the giantin threads, suggesting neurobeachin recruitment to occur on many individual foci in the immediate vicinity of the Golgi complex. Giantin-negative patches of neurobeachin recruitment in the cell periphery are also clusters of small puncta and may represent endosomal or ERGIC membranes. However, double immunofluorescence for neurobeachin or $\gamma$-adaptin versus the early-endosomal marker EEA1 displayed only a low degree of overlap (data not shown). Only a minority ( $10 \%)$ of EEA1positive structures had recruited $\gamma$-adaptin or neurobeachin, and weakly so in comparison to EEA1-negative neurobeachin and $\gamma$-adaptin patches in the periphery, and an even smaller minority of neurobeachin- or $\gamma$-adaptin-positive patches were EEA1 positive.

$\beta$-COP, $\gamma$-adaptin, $\beta$-NAP, and $\delta$-adaptin are recruited to the same gross structures as neurobeachin, but with different preferences between the Golgi vicinity and the cell periphery. Like neurobeachin, $\beta$-COP recruitment (data not shown) occurs primarily on the perinuclear ribbons, whereas the labeling of peripheral patches is faint. $\gamma$-Adaptin (Fig. 11) densely labels all perinuclear giantin-positive ribbons, but with the same intensity also decorates the giantin-negative patches in the periphery, and it forms coarser puncta than neurobeachin and the other coat proteins. $\beta$-NAP, in contrast, is more sparsely recruited to the giantinpositive structures, producing scattered clusters of puncta rather than contiguous ribbons, thus displaying an even higher preference for the cell periphery (Fig. 11) in accordance with previous observations (Simpson et al., 1996). $\delta$-Adaptin displays a distribution similar to $\beta$-NAP (data not shown). In double immunofluorescence, individual neurobeachin puncta within these gross structures are distinct from $\beta$-COP, $\gamma$-adaptin, or $\beta$-NAP puncta, respectively.

Whereas neurobeachin and these coat proteins are recruited to distinct puncta on the same gross structures, the negative control proteins RII $\alpha$ and HSB produce entirely different patterns. HSB immunofluorescence gives a pattern of fine puncta spread uni- formly across the cell (data not shown). RII $\alpha$ (Fig. 11) binds primarily to the centrosome and to mitochondria (identified, in separate double-immunofluorescence experiments not shown, with antibodies against $\gamma$-tubulin and cytochrome $c$ oxidase, respectively). Both subcellular compartments are known to carry AKAPs that may be responsible for this binding behavior (Chen et al., 1997; Schmidt et al., 1999; Takahashi et al., 1999; Witczak et al., 1999). Ribbons decorated intensely by neurobeachin occasionally also are labeled weakly by $\operatorname{RII} \alpha$, suggesting corecruitment of RII $\alpha$ to these structures via neurobeachin.

Immunofluorescence labeling of mitochondria by $\mathrm{RII} \alpha$ seems to be weaker in the presence than in the absence of GTP $\gamma \mathrm{S}$, in agreement with the slightly weaker signals also obtained by immunoblot analysis (Fig. 10). Centrosome labeling by $\gamma$-tubulin and RII $\alpha$ differs at high magnification (data not shown). Whereas $\gamma$-tubulin immunofluorescence typically forms two round dots, the $\mathrm{RII} \alpha$-positive structure is a short thread forming a circle or horseshoe around them. These observations have no bearing on neurobeachin but may be of interest for the study of mitochondria- and centrosome-associated AKAPs.

Recruitment experiments analyzed by immunofluorescence microscopy were additionally performed in the presence of ATP $\gamma \mathrm{S}$ or $\mathrm{AlF}_{4}{ }^{-}$(data not shown). ATP $\gamma \mathrm{S}$ stimulated the recruitment of neurobeachin, $\gamma$-adaptin, and $\beta$-NAP to an extent similar to GTP $\gamma \mathrm{S}$, in agreement with observations made previously on $\gamma$-adaptin (Robinson et al., 1992). $\mathrm{AlF}_{4}{ }^{-}$was found to stimulate the recruitment of $\beta$-COP but not of $\gamma$-adaptin or neurobeachin, providing an additional criterion discriminating a putative neurobeachin-associated coat from the COP-I coat.

\section{Subcellular fractionation indicates cytosolic and cytoskeletal-like subpools of brain neurobeachin}

A $120,000 \times g$ fractionation of brain homogenate showed that approximately two-thirds of total neurobeachin was recovered in the supernatant and one-third was recovered in the pellet (Fig. 12, fractions $S$ and $P$ ). The same result was obtained if $150 \mathrm{~mm} \mathrm{NaCl}$ was omitted from the homogenization buffer or replaced by $320 \mathrm{mM}$ sucrose (data not shown). From the pellet, brain neurobeachin could be extracted with neither $1 \mathrm{~m} \mathrm{NaCl}$ nor $1 \%$ Triton $\mathrm{X}-100$ but could be extracted with $0.1 \mathrm{M}$ sodium carbonate, $\mathrm{pH} 11$. In this behavior, neurobeachin differed from the intrinsic membrane protein, synaptophysin, which was almost completely solubilized by the detergent but not by sodium carbonate and was similar to the cytoskeletal control protein, tubulin (Fig. 12). Therefore, binding to salt- and detergent-resistant proteinaceous structures rather than directly to membranes seems to give rise to the sedimentable neurobeachin subpool. These observations suggest that brain neurobeachin is primarily a cytosolic protein that peripherally associates with the membranes that it decorates in immunomorphology, but a subpool is more firmly bound to a cytoskeletal-like subcellular fraction.

\section{DISCUSSION}

\section{Neurobeachin binds protein kinase A}

Neurobeachin binds RII with high affinity and specificity. Thus, neurobeachin qualifies as an AKAP, and like classical AKAPs it does not bind the type I regulatory subunit. RII binding was previously identified in the protein product of a partial Drosophila cDNA (DAKAP550) (Han et al., 1997) homologous to neurobeachin, and we show here that neurobeachin harbors an RII binding site of similar functional properties in a region colinear with the DAKAP550 RII binding site although not conserved in sequence. Vice versa, we demonstrate by completing the Drosophila cDNA sequence that it encodes a full-length neurobeachin homolog. DAKAP550 is the only full-length counterpart of both neurobeachin and BGL in the Drosophila genome. Its sequence is almost equally distant to neurobeachin and BGL, and although it is 10 -fold more abundant in fly heads than bodies, it does not seem to be as highly tissue specific as mouse neurobeachin. Like neurobeachin, it behaves as a cytosolic protein in cell fractionation but 
Figure 11. Recruitment of neurobeachin from cytosol to Golgi-near membranes is stimulated by GTP $\gamma \mathrm{S}$ and antagonized by BFA: double-immunofluorescence analysis. The localization of newly recruited neurobeachin in the presence of BFA versus GTP $\gamma \mathrm{S}$ (left $t$ right) is shown in comparison to the reference proteins (top/bottom) giantin (Golgi membranes), $\gamma$-adaptin and $\beta$-NAP (AP- 1 and AP-3 coats), and RII $\alpha$ (negative control). It can be seen that neurobeachin and the two coat proteins are recruited in a BFA/GTP $\gamma \mathrm{S}$-sensitive fashion to giantin-positive ribbons and, with different relative preferences, additionally to patches in the cell periphery. Recruitment experiments analyzed by immunofluorescence were also performed under the additional incubation conditions of Figure 10 (buffer only, cytosol only, sequential BFA and GTP $\gamma \mathrm{S}$ treatments), producing relative recruitment intensities in agreement with Figure 10 (data not shown).
BFA
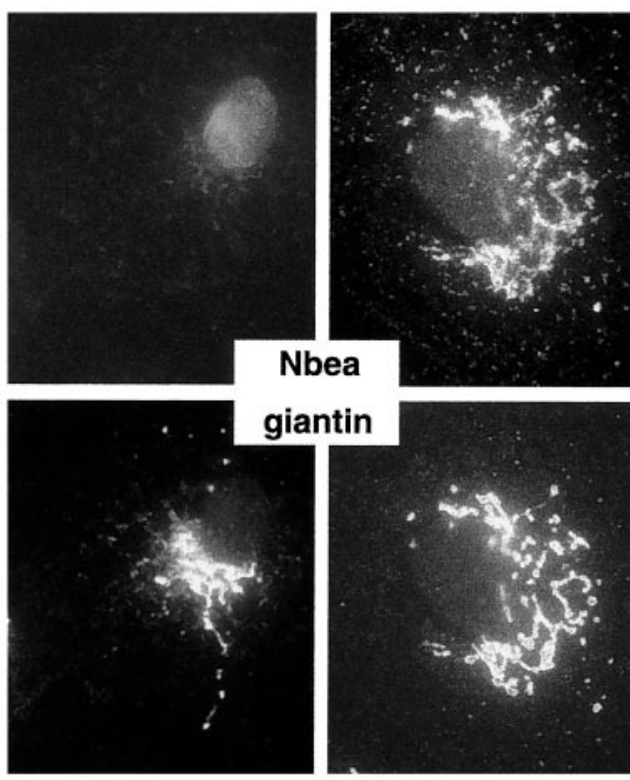

antin

\section{GTP $\gamma$}
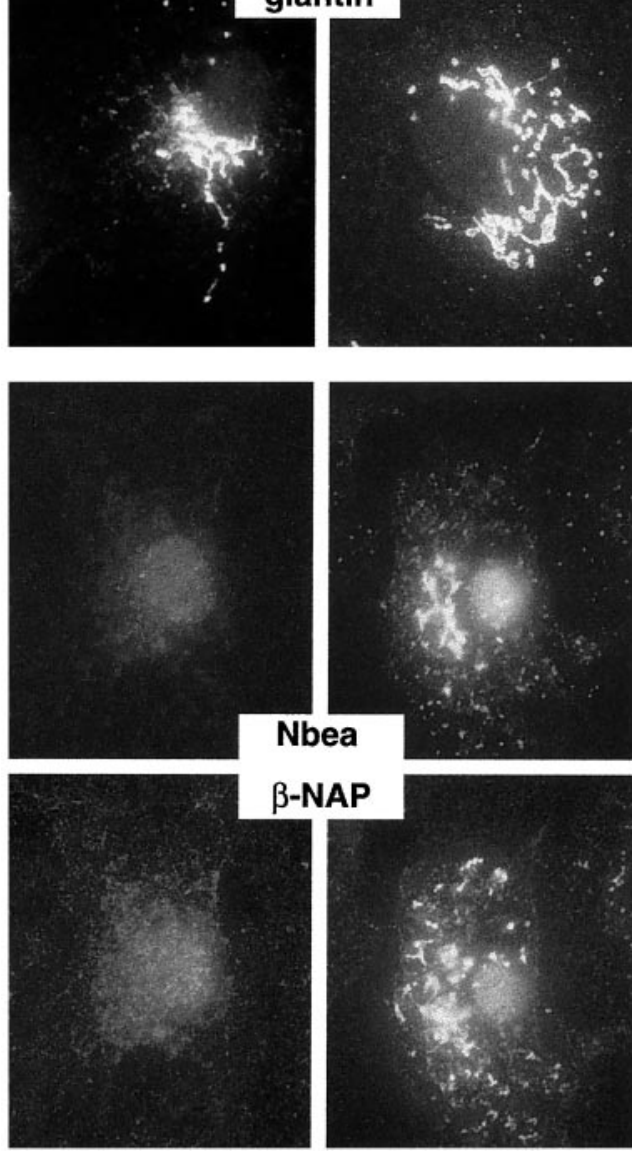

BFA
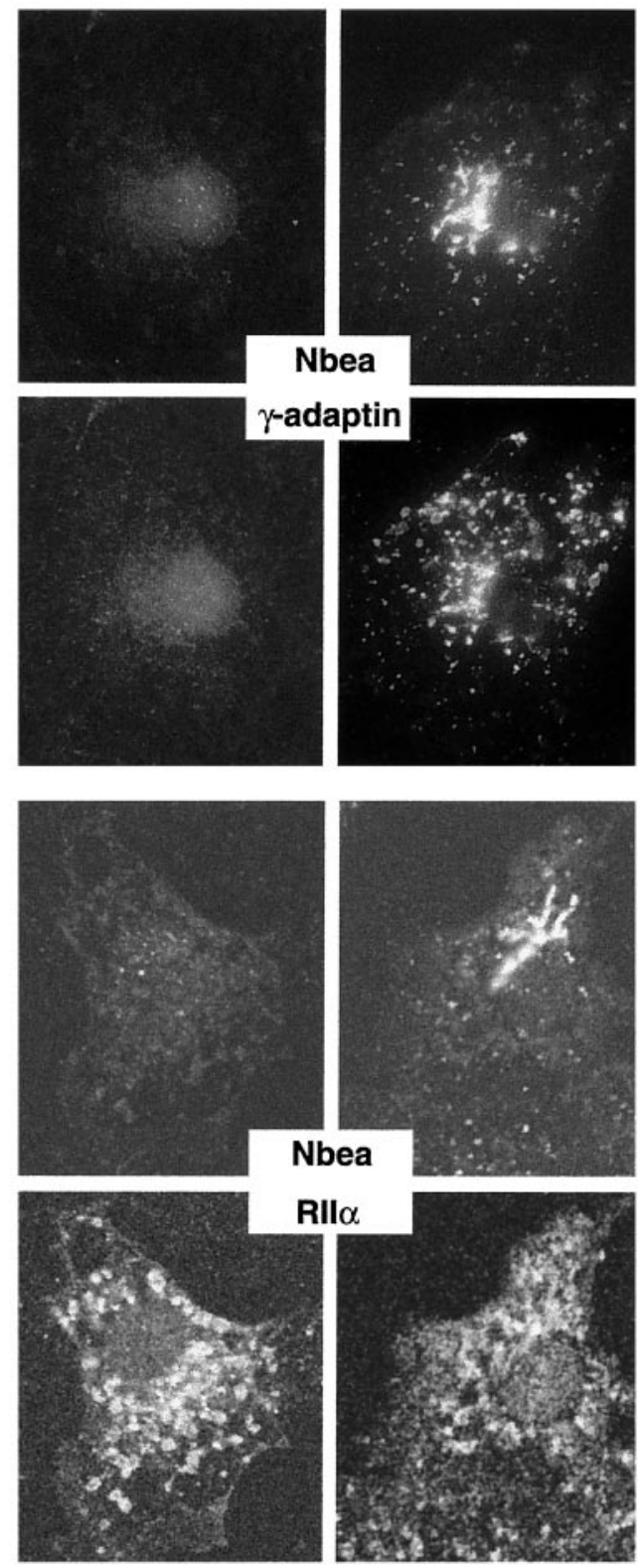

gives a granular pattern in immunolight microscopy (Han et al., 1997).

A rapidly growing number of AKAPs are recently emerging that recruit PKA to its diverse subcellular sites of action. Some AKAPs are very small and may consist only of kinase anchoring and subcellular targeting domains (Fraser et al., 1998; Gray et al., 1998), whereas others such as gravin/AKAP250 [1780 amino acids (Nauert et al., 1996)], mAKAP/AKAP100 [2319 amino acids (Kapiloff et al., 1999)], and the yotiao/AKAP350/AKAP450/CGNAP family of splice variants [1645-3908 amino acids (Schmidt et al., 1999; Takahashi et al., 1999; Witczak et al., 1999; Westphal et al., 1999)] are much larger and can be expected to have functions in addition to PKA anchoring. Such additional functions can include the possession of binding sites not only for PKA but also for other regulatory enzymes, as known for AKAP79 (Klauck et al., 1996), gravin (Nauert et al., 1996), and yotiao and CG-NAP (Takahashi et al., 1999; Westphal et al., 1999), making these molecules act as scaffolding proteins. Also, neurobeachin is a large multidomain protein and probably ties the recruitment of PKA, and thus a regulatory input by this kinase, into the context of its additional functions. The existence of the putative isoform, BGL, which presumably is functionally similar to neurobeachin but has no RII binding site in region $\mathrm{B}$, emphasizes that RII binding is only one functional facet of neurobeachin.

\section{Neurobeachin is recruited in coat protein-like fashion to trans-Golgi-near membranes: a role in membrane trafficking?}

Neurobeachin is peripherally associated with the cytoplasmic faces of tubulovesicular endomembranes, which concentrate in transGolgi-near locations but also distribute throughout the neuronal soma and dendrites, and additionally with the postsynaptic plasma membranes of some synapses. The trans-Golgi-near location suggests an association with or a possible involvement in the generation of transport organelles. Indeed, association of neurobeachin with the perinuclear, Golgi-near compartment is stimulated by GTP $\gamma \mathrm{S}$ and antagonized by BFA, and the dispersal of perinuclear neurobeachin by BFA in live cells is very rapid ( $<1 \mathrm{~min})$. This suggests that neurobeachin binds to these membranes through an ARF-dependent protein coat, or as a component of such a coat. 

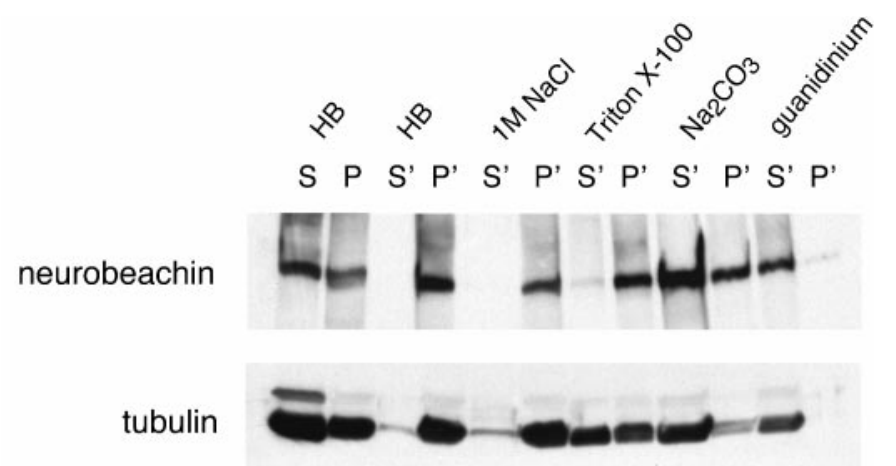

synaptophysin

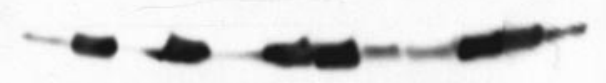

Figure 12. Subcellular fractionation indicates cytosolic and cytoskeletalassociated subpools of brain neurobeachin. Mouse brain homogenate was subjected to $120,000 \times g$ fractionation $(S$, supernatant; $P$, washed pellet $)$ in a homogenization buffer $(H B)$ containing $150 \mathrm{~mm} \mathrm{NaCl}$ as described in Materials and Methods. The pellet fraction $P$ was resuspended in the homogenization buffer $(H B)$ or in various extraction buffers $(1 \mathrm{M} \mathrm{NaCl}$ in homogenization buffer; $1 \%$ Triton X-100 in homogenization buffer without $\mathrm{NaCl} ; 100 \mathrm{~mm} \mathrm{Na} \mathrm{CO}_{3}, \mathrm{pH} 11 ; 6 \mathrm{M}$ guanidinium chloride) and recentrifuged at $120,000 \times g$. Supernatant and pellet fractions after recentrifugation are termed $S^{\prime}$ and $P^{\prime}$. Equal aliquots of all fractions were analyzed by SDS-PAGE and immunoblotting with neurobeachin, tubulin, and synaptophysin antibodies. In the experiment shown, extraction was performed at $4^{\circ} \mathrm{C}$ for $20 \mathrm{~min}$. The same distribution was obtained when extraction was performed at room temperature for $30 \mathrm{~min}$.

This putative neurobeachin-linked coat involves a BFA-sensitive GTPase but is apparently distinct from COP-I, AP-1, AP-3, or the neuronal AP-3 variant with $\beta$-NAP, because in permeabilized COS-7 cells neurobeachin and markers for these four coat types are recruited to distinct foci and with different regional preferences, albeit on the same gross endomembrane structures close to the Golgi and in the cell periphery. Neither was significant colocalization of neurobeachin with $\beta$-COP (COP-I), $\gamma$-adaptin (AP1 ), $\delta$-adaptin (AP-3), or $\beta$-NAP observed at steady state in doubleimmunofluorescence microscopy of $\mathrm{PC} 12$ cells. The recruitment of neurobeachin to membranes of COS-7 cells suggests that it interacts with molecular receptors that may normally, in these nonneuronal cells, bind BGL or other neurobeachin homologs.

Various membrane trafficking events are known to be influenced by PKA, including the generation of vesicles at the TGN for both constitutive and regulated secretion in neuroendocrine PC12 cells (Ohashi and Huttner, 1994) and for constitutive secretion in nonneuronal NRK cells (Muniz et al., 1997). The Golgi complex and TGN are major subcellular locations of RII, both in neurons (De Camilli et al., 1986) and in non-neuronal cells (Griffiths et al., 1990). In neurons, neurobeachin presumably contributes to the concentration of RII in the trans-Golgi region, but particularly in non-neuronal cells, the bulk of RII at this location is probably bound by other AKAPs such as the yotiao/AKAP350/AKAP450/ CG-NAP family. In our own double-immunofluorescence experiments with neurobeachin versus $\mathrm{RII} \alpha$ or $\mathrm{RII} \beta$ in PC12 cells (data not shown), both regulatory subunits gave punctate patterns with perinuclear clustering similar to, but no obvious colocalization of individual puncta with, neurobeachin. This also suggests that neurobeachin is responsible for the recruitment of only a fraction of RII present in the trans-Golgi region, probably targeting it selectively to specific substrate proteins and events regulated by PKA.

Many, probably most, neurobeachin-positive membrane profiles lie in the neuronal cell periphery. However, only a small proportion of GTP $\gamma$ S-stimulated recruitment occurs to Golgi-distant structures in permeabilized COS-7 cells; in live PC12 cells BFA rapidly disperses perinuclear neurobeachin, whereas punctate immunofluorescence remains visible in the cell periphery. Perhaps neu- robeachin is recruited to nascent membrane organelles primarily in the trans-Golgi region by an ARF-dependent, BFA-sensitive mechanism but remains associated with them after completion of the ARF GTPase cycle and translocation of the organelles out to the cell periphery.

Using a large number of protein markers for a wide range of endomembrane compartments, we have been unable to detect clear colocalization of any of them with neurobeachin by doubleimmunofluorescence microscopy. According to their electron microscopic morphology, neurobeachin-positive membranes in the neuronal cell periphery might be ERGIC or endosomal subcompartments or transport organelles (Hirschberg et al., 1998; Nakata et al., 1998; Burack et al., 2000; Kaether et al., 2000). The neuronspecific expression of neurobeachin could reflect a role in the trafficking of neuronal membrane proteins such as neurotransmitter receptors or ion channels. Besides the identification of neurobeachin-binding proteins in addition to RII, genetic approaches are also expected to shed light on the functions of neurobeachin and its homologs. The chromosomal locations of the human and mouse neurobeachin genes have been determined, but no loci of neurogenetic defects that map to their vicinities are known at present in man or mouse (Gilbert et al., 1999).

\section{Postsynaptic neurobeachin}

We initially identified the neurobeachin cDNA by immunoscreening with a serum raised against synaptic plasma membranes, and indeed we observe by immuno-electron microscopy an association of neurobeachin with the postsynaptic plasma membranes of some synapses. The identity of most neurobeachin-positive synapses is unclear, but among them are GABAergic synapses formed between Golgi cell terminals and granule cell dendrites in the glomeruli of the cerebellum. Within a population of morphologically similar synapses, only a few percent were neurobeachin positive. It will be of interest to clarify with which types or functional states of synapses a concentration of neurobeachin at the postsynaptic membrane is correlated.

Neurobeachin may arrive at the postsynaptic membrane in escort of transport organelles from the perikaryon or it could be part of the machinery of local postsynaptic membrane traffic. Local de novo synthesis of some neurotransmitter receptor subunits and other postsynaptic proteins (Angenstein et al., 1998; Gardiol et al., 1999; Schuman, 1999; Huber et al., 2000; Sigrist et al., 2000), the regulated exocytosis and re-endocytosis of neurotransmitter receptors (for review, see Lüscher et al., 2000; Turrigiano, 2000), and shape remodeling of the postsynaptic compartment [Okabe et al., 1999; Toni et al., 1999; Sigrist et al., 2000 (and references therein)] are recently emerging as important mechanisms in the ontogeny and plasticity of synapses. Independently of a possible role in membrane protein trafficking, neurobeachin may add to the group of postsynaptic scaffolding proteins like AKAP79, yotiao, and spinophilin, which are believed to recruit PKA and other protein kinases and phosphatases for the regulation of neurotransmitter receptors and ion channels by reversible phosphorylation (Fraser and Scott, 1999).

\section{The BEACH domain}

Neurobeachin is the fourth full-length member to be characterized of the emerging family of BEACH-WD40 proteins. The members of this family share a common architecture in which the BEACH and WD40 repeat modules are positioned at the $\mathrm{C}$ terminus, whereas the upstream sequences of most of them are dissimilar. There are at least 10 gene products with $\mathrm{BEACH}$ sequences in mammals, 5 in Drosophila, 6 in C. elegans, and several in Arabidopsis, but only 1 in $S$. cerevisiae. This suggests that BEACH-WD40 proteins exist in all eukaryotes but that the expansion to a family is a hallmark of multicellular organisms. It remains to be seen whether additional full-length homologs of neurobeachin, BGL, or LYST will be found among the as yet uncharacterized mammalian BEACH-WD40 proteins.

The function of the BEACH domain is unknown. As pointed 
out earlier (Nagle et al., 1996), its size of $\sim 280$ amino acids is much larger than a site for protein-protein interaction. It might be a protein module with, e.g., an enzymatic activity of its own. Although BGL appears to be an isoform of neurobeachin, LYST has no explicit sequence similarity with neurobeachin upstream of the BEACH domain. However, the upstream sequence of LYST is similar to neurobeachin in length and amino acid composition, including numerous hydrophobic stretches that in LYST were noted by Nagle et al. (1996) to resemble HEAT or armadillo repeats. LYST, like neurobeachin, is a cytosolic protein peripherally associating with endomembranes and the cytoskeleton (Faigle et al., 1998). It is possible, therefore, that there is a distant relationship in structure and function beyond the BEACH-WD40 region. LYST is implicated in the sorting or trafficking of multiple membrane proteins between endosomes, lysosomes, and the plasma membrane (Faigle et al., 1998; Barrat et al., 1999), and an analogous role for neurobeachin in another pathway of membrane traffic is conceivable, e.g., in the sorting, routing, or targeting of neuron-specific plasma membrane proteins. It will be of interest to see whether other BEACH domain proteins, or other AKAPs, are recruited to membranes in a GTP- and BFA-sensitive fashion like neurobeachin.

Also Dictyostelium LvsA (Kwak et al., 1999) and the functionally uncharacterized yeast BEACH protein, YCS2/BPH1 (SWISSPROT accession no. P25356, gene designation YCR032w), are large proteins of 3619 and 2167 amino acids, respectively, that have no clear sequence similarities with neurobeachin or LYST upstream of the BEACH domain but similar amino acid compositions. A short, degenerate sequence motif centered around RRYLLQNTALEVF in neurobeachin, is detectable $\sim 60-100$ amino acids upstream of the BEACH domain also in LYST, FAN, YCS2, and LvsA (Fig. 1). A genetic defect of LvsA perturbs plasma membrane dynamics, causing an arrest during the course of cytokinesis and instead the formation of a large plasma membrane bulge (Kwak et al., 1999). The molecular mechanisms underlying this phenotype are unknown. FAN, which mediates receptorinduced activation of neutral sphingomyelinase, has only a short upstream sequence, and there are no indications for a role of FAN in membrane protein trafficking. An involvement, directly or indirectly, in the modulation of local membrane lipid composition may be a common denominator of neurobeachin, LYST, LvsA, and FAN.

\section{REFERENCES}

Adam-Klages S, Adam D, Wiegmann K, Struve S, Kolanus W, SchneiderMergener J, Krönke M (1996) FAN, a novel WD-repeat protein, couples the p55 TNF-receptor to neutral sphingomyelinase. Cell 86:937-947.

Angenstein F, Greenough WT, Weiler IJ (1998) Metabotropic glutamate receptor-initiated translocation of protein kinase p90rsk to polyribosomes: a possible factor regulating synaptic protein synthesis. Proc Natl Acad Sci USA 95:15078-15083.

Barrat FJ, Le Deist F, Benkerrou M, Bousso P, Feldmann J, Fischer A, de Saint Basile G (1999) Defective CTLA-4 cycling pathway in ChediakHigashi syndrome: a possible mechanism for deregulation of T lymphocyte activation. Proc Natl Acad Sci USA 96:8645-8650.

Buechler YL, Herberg FW, Taylor SS (1993) Regulation-defective mutants of type I cAMP-dependent protein kinase. J Biol Chem 268:16495-16503.

Burack MA, Silverman MA, Banker G (2000) The role of selective transport in neuronal protein sorting. Neuron 26:465-472.

Burkhardt JK, Wiebel FA, Hester S, Argon Y (1993) The giant organelles in beige and Chediak-Higashi fibroblasts are derived from late endosomes and mature lysosomes. J Exp Med 178:1845-1856.

Burry RW, Vandre DD, Hayes DM (1992) Silver enhancement of gold antibody probes in pre-embedding electron microscopic immunocytochemistry. J Histochem Cytochem 40:1849-1856.

Carr DW, Hausken ZE, Fraser IDC, Stofko-Hahn RE, Scott JD (1992) Association of the type II cAMP-dependent protein kinase with a human thyroid RII-anchoring protein. J Biol Chem 267:13376-13382.

Chen Q, Lin RY, Rubin CS (1997) Organelle-specific targeting of protein kinase AII (PKAII): molecular and in situ characterization of murine A kinase anchor proteins that recruit regulatory subunits of PKAII to the cytoplasmic surface of mitochondria. J Biol Chem 272:15247-15257.

Colledge M, Scott JD (1999) AKAPs: from structure to function. Trends Cell Biol 9:216-221.
De Camilli P, Moretti M, Donini SD, Walter U, Lohmann SM (1986) Heterogeneous distribution of the cAMP receptor protein RII in the nervous system: evidence for its intracellular accumulation on microtubules, microtubule-organizing centers, and in the area of the Golgi complex. J Cell Biol 103:189-203.

Dell'Angelica EC, Mullins C, Caplan S, Bonifacino JS (2000) Lysosomerelated organelles. FASEB J 14:1265-1278.

Faigle W, Raposo G, Tenza D, Pinet V, Vogt AB, Kropshofer H, Fischer A, de Saint-Basile G, Amigorena S (1998) Deficient peptide loading and MHC class II endosomal sorting in a human genetic immunodeficiency disease: the Chediak-Higashi syndrome. J Cell Biol 141:1121-1134.

Feuchter AE, Freeman JD, Mager DL (1992) Strategy for detecting cellular transcripts promoted by human endogenous long terminal repeats: identification of a novel gene (CDC4L) with homology to yeast CDC4. Genomics 13:1237-1246.

Foletti DL, Prekeris R, Scheller RH (1999) Generation and maintenance of neuronal polarity: mechanisms of transport and targeting. Neuron 23:641-644.

Fraser IDC, Scott JD (1999) Modulation of ion channels: a "current" view of AKAPs. Neuron 23:423-426.

Fraser IDC, Tavalin SJ, Lester LB, Langeberg LK, Westphal AM, Dean RA, Marrion NV, Scott JD (1998) A novel lipid-anchored A-kinase anchoring protein facilitates cAMP-responsive membrane events. EMBO J 17:2261-2272.

Gardiol A, Racca C, Triller A (1999) Dendritic and postsynaptic protein synthetic machinery. J Neurosci 19:168-179.

Gilbert DJ, Engel H, Wang X, Grzeschik KH, Copeland NG, Jenkins NA, Kilimann MW (1999) The neurobeachin gene (Nbea) identifies a new region of homology between mouse central chromosome 3 and human chromosome 13q13. Mamm Genome 10:1030-1031.

Gray PC, Johnson BD, Westenbroek RE, Hays LG, Yates JR, Scheuer T, Catterall WA, Murphy BJ (1998) Primary structure and function of an A kinase anchoring protein associated with calcium channels. Neuron 20:1017-1026

Griffiths G, Hollinshead R, Hemmings BA, Nigg EA (1990) Ultrastructural localization of the regulatory (RII) subunit of cyclic AMPdependent protein kinase to subcellular compartments active in endocytosis and recycling of membrane receptors. J Cell Sci 96:691-703.

Han J-D, Baker NE, Rubin CS (1997) Molecular characterization of a novel A kinase anchor protein from Drosophila melanogaster. J Biol Chem 272:26611-26619.

Herberg FW, Maleszka A, Eide T, Vossebein L, Tasken K (2000) Analysis of A-kinase anchoring protein (AKAP) interaction with protein kinase A (PKA) regulatory subunits: PKA isoform specificity in AKAP binding. J Mol Biol 298:329-339.

Hirschberg K, Miller CM, Ellenberg J, Presley JF, Siggia ED, Phair RD, Lippincott-Schwartz J (1998) Kinetic analysis of secretory protein traffic and characterization of Golgi to plasma membrane transport intermediates in living cells. J Cell Biol 143:1485-1503.

Hoesche C, Bartsch P, Kilimann MW (1995) The CRE consensus sequence in the synapsin I gene promoter region confers constitutive activation but no regulation by cAMP in neuroblastoma cells. Biochim Biophys Acta 1261:249-256.

Huber KM, Kayser MS, Bear MF (2000) Role for rapid dendritic protein synthesis in hippocampal mGluR-dependent long-term depression. Science 288:1254-1256.

Kaether C, Skehel P, Dotti CG (2000) Axonal membrane proteins are transported in distinct carriers: a two-color video microscopy study in cultured hippocampal neurons. Mol Biol Cell 11:1213-1224.

Kapiloff MS, Schillace RV, Westphal AM, Scott JD (1999) mAKAP: an A-kinase anchoring protein targeted to the nuclear membrane of differentiated myocytes. J Cell Sci 112:2725-2736.

Klauck TM, Faux MC, Labudda K, Langeberg LK, Jaken S, Scott JD (1996) Coordination of three signaling enzymes by AKAP79, a mammalian scaffold protein. Science 271:1589-1592.

Kutzleb C, Sanders G, Yamamoto R, Wang X, Lichte B, Petrasch-Parwez E, Kilimann MW (1998) Paralemmin, a prenyl-palmitoyl anchored phosphoprotein abundant in neurons and implicated in plasma membrane dynamics and cell process formation. J Cell Biol 143:795-813

Kwak E, Gerald N, Larochelle DA, Vithalani KK, Niswonger ML, Maready M, De Lozanne A (1999) LvsA, a protein related to the mouse beige protein, is required for cytokinesis in Dictyostelium. Mol Biol Cell 10:4429-4439.

Lichte B, Veh RW, Meyer HE, Kilimann MW (1992) Amphiphysin, a novel protein associated with synaptic vesicles. EMBO J 11:2521-2530.

Lüscher C, Nicoll RA, Malenka RC, Muller D (2000) Synaptic plasticity and dynamic modulation of the postsynaptic membrane. Nat Neurosci 3:545-550.

Muniz M, Martin ME, Hidalgo J, Velasco A (1997) Protein kinase A activity is required for the budding of constitutive transport vesicles from the trans-Golgi network. Proc Natl Acad Sci USA 94:14461-14466.

Nagle DL, Karim MA, Woolf EA, Holmgren L, Bork P, Misumi DJ, McGrail SH, Dussault BJ, Perou CM, Boissy RE, Duyk GM, Spritz RA, Moore KJ (1996) Identification and mutation analysis of the complete gene for Chediak-Higashi syndrome. Nat Genet 14:307-311.

Nakata T, Terada S, Hirokawa N (1998) Visualization of the dynamics of 
synaptic vesicle and plasma membrane proteins in living axons. J Cell Biol 140:659-674.

Nauert JB, Klauck TM, Langeberg LK, Scott JD (1996) Gravin, an autoantigen recognized by serum from myasthenia gravis patients, is a kinase scaffold protein. Curr Biol 7:52-62.

Ohashi M, Huttner WB (1994) An elevation of cytosolic protein phosphorylation modulates trimeric G-protein regulation of secretory vesicle formation from the trans-Golgi network. J Biol Chem 269:24897-24905.

Okabe S, Kim HD, Miwa A, Kuriu T, Okado H (1999) Continual remodeling of postsynaptic density and its regulation of synaptic activity. Nat Neurosci 2:804-811.

Perou CM, Moore KJ, Nagle DL, Misumi DJ, Woolf EA, McGrail SH, Holmgren L, Brody TH, Dussault BJ, Monroe CA, Duyk GM, Pryor RJ, Li L, Justice MJ, Kaplan J (1996) Identification of the murine beige gene by YAC complementation and positional cloning. Nat Genet 13:303-308.

Perou CM, Leslie JD, Green W, Li L, McVey Ward D, Kaplan J (1997) The beige/Chediak-Higashi syndrome gene encodes a widely expressed cytosolic protein. J Biol Chem 272:29790-29794.

Robinson MS, Kreis TE (1992) Recruitment of coat proteins onto Golgi membranes in intact and permeabilized cells: effects of brefeldin A and G protein activators. Cell 69:129-138.

Schmidt PH, Dransfield DT, Claudio JO, Hawley RG, Trotter KW, Milgram SL, Goldenring JR (1999) AKAP350, a multiply spliced protein kinase A-anchoring protein associated with centrosomes. J Biol Chem 274:3055-3066.

Schuman EM (1999) mRNA trafficking and local protein synthesis at the synapse. Neuron 23:645-648.

Seaman MNJ, Ball CL, Robinson MS (1993) Targeting and mistargeting of plasma membrane adaptors in vitro. J Cell Biol 123:1093-1105.

Sigrist SJ, Thiel PR, Reiff DF, Lachance PED, Lasko P, Schuster CM (2000) Postsynaptic translation affects the efficacy and morphology of neuromuscular junctions. Nature 405:1062-1065.

Simpson F, Bright NA, West MA, Newman LS, Darnell RB, Robinson MS (1996) A novel adaptor-related protein complex. J Cell Biol 133:749-760.
Springer S, Spang A, Schekman R (1999) A primer on vesicle budding. Cell 97:145-148.

Stenberg E, Persson B, Roos H, Urbaniczky C (1991) Quantitative determination of surface concentration of protein with surface plasmon resonance by using radiolabeled protein. J Colloid Interface Sci 143:513-526.

Takahashi M, Shibata H, Shimakawa M, Miyamoto M, Mukai H, Ono Y (1999) Characterization of a novel giant scaffolding protein, CG-NAP, that anchors multiple signaling enzymes to centrosome and the Golgi apparatus. J Biol Chem 274:17267-17274.

Toni N, Buchs PA, Nikonenko I, Bron CR, Muller D (1999) LTP promotes formation of multiple spine synapses between a single axon terminal and a dendrite. Nature 402:421-425.

Turrigiano GG (2000) AMPA receptors unbound: membrane cycling and synaptic plasticity. Neuron 26:5-8.

Westphal RS, Tavalin SJ, Lin JW, Alto NM, Fraser IDC, Langeberg LK, Sheng M, Scott JD (1999) Regulation of NMDA receptors by an associated phosphatase-kinase signaling complex. Science 285:93-96.

Wicksteed BL, Roberts AB, Sagliocco FA, Brown AJ (1991) The complete sequence of a $7.5 \mathrm{~kb}$ region of chromosome III from Saccharomyces cerevisiae that lies between CRY1 and MAT. Yeast 7:761-772.

Wilson R, Ainscough R, Anderson K, Baynes C, Berks M, Bonfield J, Burton J, Connell M, Copsey T, Cooper J, Coulson A, Craxton M, Dear S, Du Z, Durbin R, Favello A, Fraser A, Fulton L, Gardner A, Green P, Hawkins T, Hillier L, Jier M, Johnston L, Jones M, Kershaw J, Kirsten J, Laisster N, Latreille P, Lightning J, Lloyd C, Mortimore B, O'Callaghan M, Parsons J, Percy C, Rifken L, Roopra A, Saunders D, Shownkeen R, Sims M, Smaldon N, Smith A, Smith M, Sonnhammer E, Staden R, Sulston J, Thierry-Mieg J, Thomas K, Vaudin M, Vaughan K, Waterston R, Watson A, Weinstock L, Wilkinson-Sproat J, Wohldman P (1994) 2.2 $\mathrm{Mb}$ of contiguous nucleotide sequence from chromosome III of $C$. elegans. Nature 368:32-38.

Witczak O, Skalhegg BS, Keryer G, Bornens M, Tasken K, Jahnsen T, Örstavik S (1999) Cloning and characterization of a cDNA encoding an A-kinase anchor protein located in the centrosome, AKAP450. EMBO J 18:1858-1868. 